\title{
Synthesis and preliminary biological evaluation of new phenolic and catecholic dehydroamino acid derivatives
}

\author{
Luís S. Monteiro $^{\mathrm{a}, *}$, Sandra Oliveira ${ }^{\mathrm{a}, \mathrm{b}}$, Fátima Paiva-Martins ${ }^{\mathrm{b}}$, Paula M.T. Ferreira ${ }^{\mathrm{a}}$, David M. Pereira ${ }^{\mathrm{c}}$, \\ Paula B. Andrade ${ }^{c}$, Patrícia Valentão ${ }^{c}$ \\ ${ }^{a}$ Chemistry Centre, University of Minho, Campus de Gualtar, 4710-057 Braga, Portugal \\ ${ }^{b}$ REQUIMTE/LAQV, Department of Chemistry and Biochemistry, Faculty of Science, University of Porto, Rua do Campo Alegre 687, Porto, Portugal. \\ ${ }^{c}$ REQUIMTE/LAQV, Laboratory of Pharmacognosy, Department of Chemistry, University of Porto, Rua de Jorge Viterbo Ferreira 228, 4050-213 Porto, \\ Portugal
}

\section{ARTICLE INFO}

Article history:

Received

Received in revised form

Accepted

Available online

\section{Keywords:}

Catechol

Dehydroamino acids

tert-Butyloxycarbonylation

Dehydration

Cell viability studies

\section{ABSTRACT}

\begin{abstract}
A library of $N$-phenolic and $N$-catecholic dehydroamino acid derivatives was prepared using an innovative synthetic strategy that involves mild reaction conditions and simple work-up procedures. The method comprises coupling of phenolic or catecholic acids with $\beta$ hydroxyamino acids followed by tert-butyloxycarbonylation of all hydroxyl groups using tertbutyldicarbonate and 4-dimethylaminopyridine as catalyst. Treatment of these amino acids with $N, N, N$ ', $N$ '-tetramethylguanidine affords the corresponding $O$-tert-butyloxycarbonyldehydroamino acid derivative. Deprotection of the aromatic hydroxyl groups is carried out with trifluoroacetic acid. This synthetic strategy can be applied in a one-pot procedure and yields compounds that can be easily inserted into peptides or other biomolecules after cleavage of the $C$-protecting group. Preliminary studies of cell viability show that these new compounds display very low or no toxicity. These dehydroamino acids with a phenolic or catecholic moiety can have intrinsic biological activity or used to prepare new hydrogels that mimic mussel adhesive proteins.
\end{abstract}

2017 Elsevier Ltd. All rights reserved.

\section{Introduction}

Phenolic acids coupled with amino acids or amines can be obtained from natural sources or synthetically. It is assumed that these bioactive substances are involved in suppression of deleterious effects of oxidative stress and have a wide range of biological activities such as antioxidant, ${ }^{1-5}$ anticancer ${ }^{6}$ and antimicrobial. ${ }^{7-12}$ In fact, the accumulation of hydroxycinnamic acid amides constitutes part of the defence system of plants that is activated as response to various environmental stimuli such as wounding, fungal infection or heavy metal ions. ${ }^{13-16}$ Lee et al. prepared a series of cinnamic acid derivatives and evaluated their biological activities in lipoprotein metabolism. ${ }^{17}$ The methyl esters of $\mathrm{N}$-(4hydroxycinnamoyl)- $L$-phenylalanine and the dibenzyl ester of $\mathrm{N}$-caffeoyl-aspartic acid showed potent anti-atherogenic and antioxidant activities. Moreover, amides of cinnamic, ferulic and sinapic acids with natural and unnatural $C$ protected amino acids have been synthesized and also showed antimicrobial activity, radical scavenging activity against the free 2,2-diphenyl-1-picrylhydrazyl radical and antioxidant activity in bulk oil. ${ }^{18-19}$

Several studies suggest that a cocktail of antioxidants, endowed with different molecular structures and mechanisms of action, result more effective than a single antioxidant, due to the synergic effect between different types of molecules. ${ }^{20-26}$ To highlight possible synergic mechanisms and to better understand mechanistic aspects, the design of modified and/or dualistic molecules is a valuable approach. Studies have confirmed that conjugation between different types of compounds such as amino acids with phenolic acids is useful, not only to investigate structure-activity relationships, but can also constitute a ${ }_{29}$ strategy to improve antioxidant efficiency and bioactivity. ${ }^{27-}$

Another application of phenolic or catecholic amino acids is in the design of new peptide hydrogels that mimic mussel adhesive proteins. ${ }^{30}$ The extraordinary ability of mussel adhesive proteins is mainly attributed to the reversible metal-catechol coordination between metals like $\mathrm{Fe}^{3+}$ and catechol groups from the amino acid 3,4dihydroxyphenyl- $L$-alanine (DOPA), and also to other interactions such as cation- $\pi$ interactions. ${ }^{31}$ Recently, a new type of injectable hydrogel based on self-assembly of an $A B A$ tri-block copolymer with rapid self-healing properties through mussel-inspired catechol-mediated hydrogen bonding interactions and aromatic interactions and with antibiofouling capability was described. ${ }^{32}$ 
Non-coded amino acids can have a variety of applications such as in structure-activity relationship studies, as antiviral, antitumor, anti-inflammatory or immunosuppressor compounds or in the development of new biomaterials. ${ }^{33-35}$ In particular, dehydroamino acids constitute an important class of non-proteinogenic amino acids with various biological activities including antioxidant. ${ }^{36-48}$ In general, the presence of one or more $\alpha, \beta$ dehydroamino acid in a polypeptide chain has strong impact, not only on the secondary structure adopted, but also on their biological behaviour, including antibacterial, antifungal and antitumor activities ${ }^{36-38}$ and resistance to proteolysis. Recently, several low molecular weight dehydrodipeptide hydrogelators were prepared and studied as new drug delivery systems. ${ }^{49,50}$ Thus, the combination of phenolic or catecholic moieties with dehydroamino acids can be a valuable approach to the development of new biologically active compounds

In our laboratories we developed an efficient method for the synthesis of $N, N$-diacyl- $\alpha, \beta$-dehydroamino acid derivatives by using two equivalents of tertbutyldicarbonate $\left(\mathrm{Boc}_{2} \mathrm{O}\right)$ and 4-dimethylaminopyridine (DMAP) as catalyst in dry acetonitrile. ${ }^{51}$ In order to allow the synthesis of $\mathrm{N}$-monoprotected dehydroamino acid derivatives, a modification of this method was subsequently reported. $^{52}$ Thus, by reacting $\beta$-hydroxyamino acid derivatives with one equivalent of $\mathrm{Boc}_{2} \mathrm{O}$ and DMAP it was possible to obtain the corresponding $\beta$-carbonates that undergo $\beta$-elimination by treatment with $N, N, N^{\prime}, N^{\prime}$ tetramethylguanidine (TMG).

In this work and in order to explore the effect of combining a dehydroamino acid moiety with phenolic or catecholic acids, an innovative strategy for the synthesis of these conjugates was developed. This new methodology involves the simultaneous tert-butyloxycarbonylation of all hydroxyl groups present in the $N$-protected $\beta$-hydroxyamino acids followed by a selective $\beta$-elimination reaction and cleavage of the aromatic $O$-tert-butyloxycarbonyl groups. The non-coded amino acids prepared can have biological activity or can be use in the design of new peptide hydrogels that mimic mussel adhesive proteins.

\section{Results and Discussion}

The methyl ester of $N$-(4-hydroxybenzoyl) dehydroalanine was prepared from 4-hydroxybenzoic acid (a) and the methyl ester of serine (1). The coupling between $\mathbf{a}$ and $\mathbf{1}$ was carried out using 2-(1H-benzotriazol-1-yl)-1,1,3,3tetramethyluronium hexafluorophosphate (HBTU) and 1hydroxybenzotriazole (HOBt) to give the methyl ester of $\mathrm{N}$ (4-hydroxybenzoyl)serine in $71 \%$ yield (Scheme 1, compound 1a). This compound was treated with two equivalents of $\mathrm{Boc}_{2} \mathrm{O}$ and DMAP as catalyst in acetonitrile to afford compound $\mathbf{2 a}$ (Scheme 1). In the proton NMR spectrum of this compound it is possible to observe two singlets at $1.47 \mathrm{ppm}$ and $1.57 \mathrm{ppm}$ that correspond to the protons of the two tert-butyloxycarbonyl (Boc) groups. Compound 2a was reacted with a solution of TMG in acetonitrile to give the dehydroalanine derivative $\mathbf{3 a}$ in $31 \%$ yield (Scheme 1). The proton NMR spectrum of 3a shows two singlets at $6.01 \mathrm{ppm}$ and $6.79 \mathrm{ppm}$ caracteristic of the $\beta$ $\mathrm{CH}_{2}$ protons of dehydroalanine. Cleavage of the aromatic $O$ Boc group from 3a was accomplished using trifluoroacetic acid, giving compound $\mathbf{4 a}$ in $47 \%$ yield (Scheme 1).

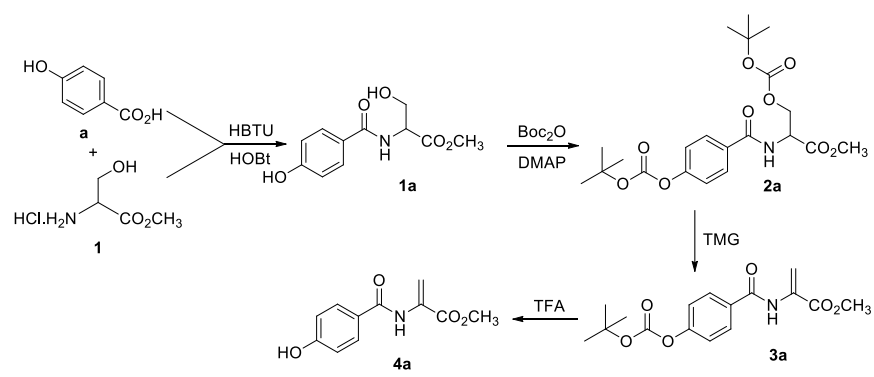

Scheme 1. Synthesis of the methyl ester of $N$-(4-hydroxybenzoyl) dehydroalanine.

In order to improve the low overall yield, a one-pot procedure was tested. Thus, compound 1a was used in a sequential reaction with $\mathrm{Boc}_{2} \mathrm{O} / \mathrm{DMAP}$, followed by TMG and finally TFA. Compound $\mathbf{4 a}$ was isolated in $47 \%$ yield (Scheme 2, Table 1).

The same methodology was applied with the methyl ester of serine and other phenolic and catecholic acids to give the dehydroalanine derivatives $\mathbf{4 c}, \mathbf{4 e}$ and $\mathbf{4 f}$ (Scheme 2, Table 1). Although attempted, it was impossible to isolate the coupling products between serine and protocatechuic acid (b), 2-(3,4-dihydroxyphenyl) acetic acid (d), hydrocaffeic acid (g) and gallic acid (h). This may be due to the high hydrophilic character of compounds $\mathbf{1 b}, \mathbf{1 d}, \mathbf{1 g}$ and 1h when compared with the other serine derivatives (compounds 1a, 1c, 1e and 1f). 


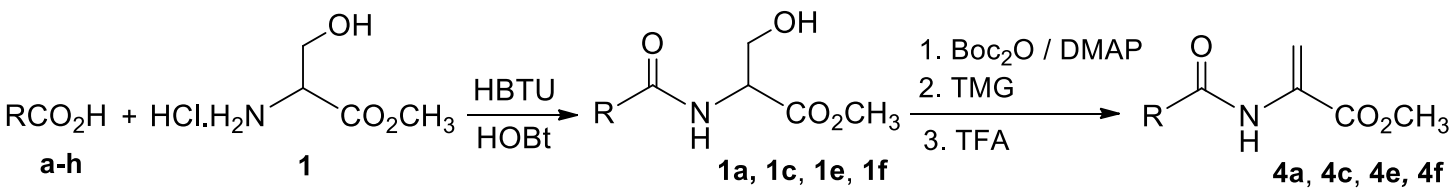

$\mathrm{RCO}_{2} \mathrm{H}$

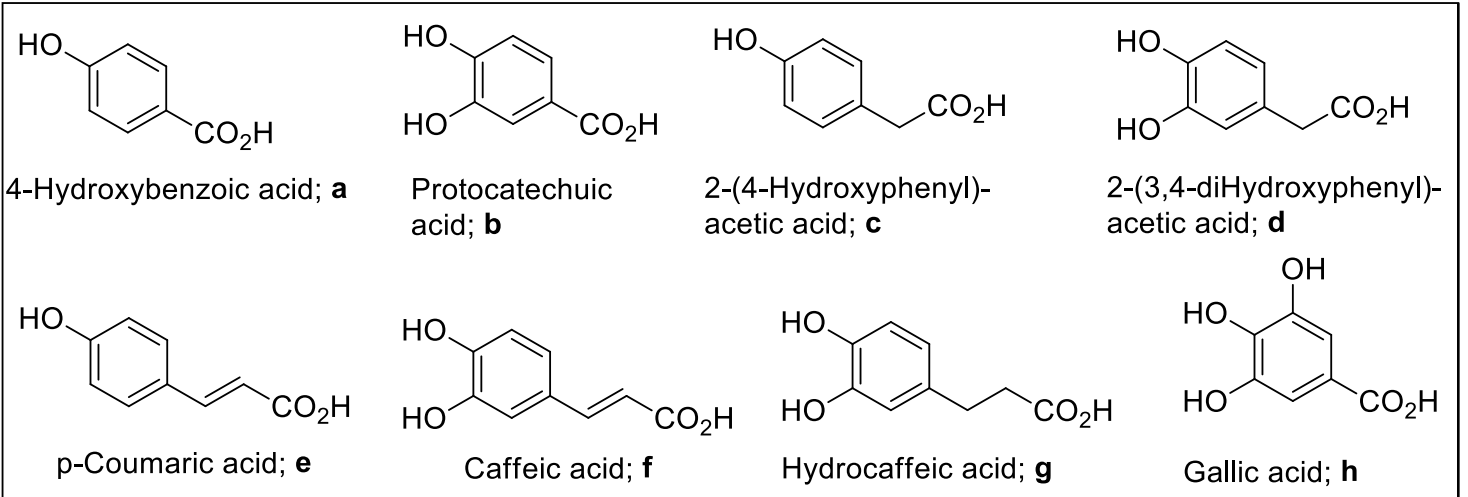

Scheme 2. One-pot procedure used in the synthesis of the methyl esters of $N$-phenoyl and $N$-catechoyl dehydroalanine.

Table 1

Yields obtained in the synthesis of the methyl esters of $N$-phenoyl and $N$-catechoyl serine and in the synthesis of the corresponding dehydroalanine derivatives using a one-pot procedure.

\begin{tabular}{|c|c|c|c|}
\hline $\begin{array}{l}\text { Phenolic or catecholic serine } \\
\text { derivative }\end{array}$ & $\begin{array}{c}\text { Yield } \\
(\%)\end{array}$ & $\begin{array}{l}\text { Phenolic or catecholic dehydroalanine } \\
\text { derivative }\end{array}$ & $\begin{array}{l}\text { Yield } \\
(\%)\end{array}$ \\
\hline 4-Hydroxybenzoyl-L-Ser-OMe, $\mathbf{1 a}$ & 71 & 4-Hydroxybenzoyl- $\Delta$ Ala-OMe, $\mathbf{4}^{\text {a }}$ & 47 \\
\hline 2-(4-Hydroxyphenyl)acetoyl- $L$-Ser-OMe, 1c & 52 & 2-(4-Hydroxyphenyl)acetoyl- $\Delta$ Ala-OMe, $\mathbf{4 c}$ & 36 \\
\hline$p$-Coumaroyl- $L$-Ser-OMe, $\mathbf{1 e}$ & 57 & $p$-Coumaroyl- $\Delta$ Ala-OMe, $\mathbf{4 e}$ & 68 \\
\hline Caffeoyl- $L-$ Ser-OMe, $\mathbf{1 f}$ & 71 & Caffeoyl- $\Delta$ Ala-OMe, $\mathbf{4 f}$ & 26 \\
\hline
\end{tabular}

The same approach was applied to the synthesis of dehydrophenylalanine derivatives $N$-capped with phenolic or catecholic acids. Thus, the methyl ester of $N$ caffeoylphenylserine was prepared by coupling caffeic acid (f) with the methyl ester of phenylserine (5) to give compound $\mathbf{5 f}$ (Scheme 3). Compound $\mathbf{5 f}$ was treated with three equivalents of $\mathrm{Boc}_{2} \mathrm{O}$ and DMAP to give compound 6f. The three singlets corresponding to the 27 protons of the three Boc groups were observed in the proton NMR spectrum at $1.47,1.56$ and $1.57 \mathrm{ppm}$. Compound $\mathbf{6 f}$ was reacted with TMG to give dehydrophenylalanine $\mathbf{7 f}$ which gave $\mathbf{8 f}$ after cleavage of the aromatic $O$-Boc groups. The dehydrophenylalanine derivative was obtained in $29 \%$ overall yield (Scheme 3).

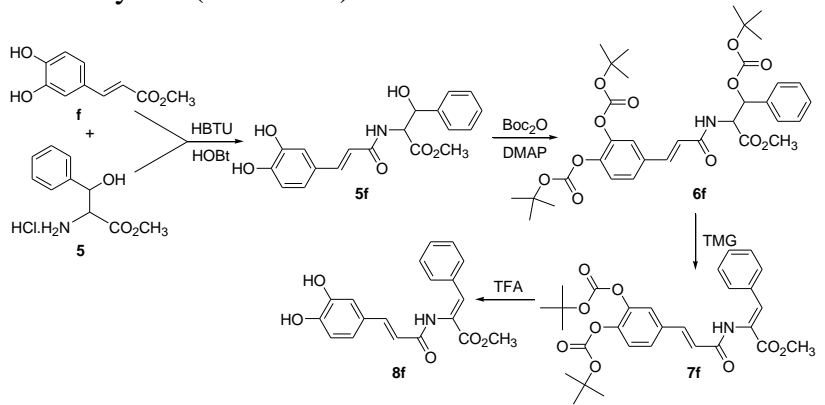

Scheme 3. Synthesis of the methyl ester of $N$ caffeoyldehydrophenyl-alanine.

As observed for the dehydroalanine derivatives the overall yield in compound $\mathbf{5 f}$ was considerably improved using the one-pot procedure (Scheme 4, Table 2). Thus, all other phenolic and catecholic acids (a-e, g, h) were reacted with the methyl ester of phenylserine. The lower hidrophylicity of the phenylserine derivatives obtained, allowed the preparation of all $N$-protected phenylserine derivatives in good yields (Scheme 4, Table 2, compounds 5a-e, 5g, 5h). The one-pot procedure was carried out with all $N$-protected phenylserine derivatives to give the Z-isomer of the corresponding dehydrophenylalanine derivative (Scheme 4, Table 2, compounds 8a-e, 8g). The stereochemistry of the dehydrophenylalanine moieties was confirmed using NOE difference experiments by irradiating the $\mathrm{OMe}$ protons and observing an NOE enhancement on the signal of the $\beta$-CH proton. The $N$-galloyl phenylserine derivative (compound $\mathbf{5 h}$ ) was treated in the same conditions but the only product isolated was $\mathrm{N}$ deprotected dehydrophenylalanine (H-Z- $\Delta \mathrm{Phe}-\mathrm{OMe}$ ) This probably resulted from the higher nucleophilic character of the amide nitrogen of the galloyl derivative, which led to the preferential tert-butyloxycarbonylation of the amide, making the galloyl group susceptible to cleavage by TMG. This was described by Ragnarsson and co-workers for cleavage of acyl groups from $N$-acyl- $N$ Boc-amines. ${ }^{54}$ The subsequent treatment with TFA of the $\mathrm{N}$-tert-butyloxycarbonyl dehydrophenylalanine formed led to the methyl ester of dehydrophenylalanine. 
<smiles>[R]C(=O)N/C(=C/c1ccccc1)C(=O)OCC(C)=O</smiles>

Scheme 4. One-pot procedure used in the synthesis of the methyl esters of $N$-phenoyl and $N$-catechoyl dehydrophenylalanine.

Table 2

Yields obtained in the synthesis of the methyl esters of $N$-phenoyl and $N$-catechoyl phenylserine and in the synthesis of the corresponding dehydrophenylalanine derivatives using a one-pot procedure.

\begin{tabular}{|c|c|c|c|}
\hline $\begin{array}{l}\text { Phenolic or catecholic phenylserine } \\
\text { derivative }\end{array}$ & $\begin{array}{c}\text { Yield } \\
(\%)\end{array}$ & $\begin{array}{l}\text { Phenolic or catecholic dehydrophenylalanine } \\
\text { derivative }\end{array}$ & $\begin{array}{l}\text { Yield } \\
(\%)\end{array}$ \\
\hline 4-Hydroxybenzoyl- $D, L$-Phe( $\beta$-OH)-OMe, 5a & 96 & 4-Hydroxybenzoyl-Z- $\Delta$ Phe-OMe, 8a & 57 \\
\hline Protocatechoyl- $D, L-\mathrm{Phe}(\beta-\mathrm{OH})-\mathrm{OMe}, \mathbf{5 b}$ & 86 & Protocatechoyl-Z- $\Delta$ Phe-OMe, $\mathbf{8 b}$ & 21 \\
\hline 2-(4-Hydroxyphenyl)acetoyl- $D, L-\mathrm{Phe}(\beta-\mathrm{OH})-\mathrm{OMe}, \mathbf{5 c}$ & 89 & 2-(4-Hydroxyphenyl)acetoyl-Z- $\Delta$ Phe-OMe, 8c & 63 \\
\hline 2-(3,4-diHydroxyphenyl)acetoyl- $D, L-\mathrm{Phe}(\beta-\mathrm{OH})-\mathrm{OMe}, \mathbf{5 d}$ & 86 & 2-(3,4-diHydroxyphenyl)acetoyl-Z- $\Delta \mathrm{Phe}-\mathrm{OMe}, \mathbf{8 d}$ & 43 \\
\hline$p$-Coumaroyl- $D, L$-Phe $(\beta-\mathrm{OH})-\mathrm{OMe}, \mathbf{5 e}$ & 80 & $p$-Coumaroyl-Z- $\Delta$ Phe-OMe, $8 \mathbf{e}$ & 60 \\
\hline Caffeoyl- $D, L-\mathrm{Phe}(\beta-\mathrm{OH})-\mathrm{OMe}, \mathbf{5 f}$ & 97 & Caffeoyl-Z- $\Delta$ Phe-OMe, $\mathbf{8 f}$ & 55 \\
\hline Hydrocaffeoyl- $D, L$-Phe( $\beta$-OH)-OMe, 5g & 89 & Hydrocaffeoyl-Z- $\Delta$ Phe-OMe, $8 \mathbf{g}$ & 52 \\
\hline Galloyl- $D, L-\mathrm{Phe}(\beta-\mathrm{OH})-\mathrm{OMe}, \mathbf{5 h}$ & 76 & Galloyl-Z- $\Delta$ Phe-OMe, $\mathbf{8 h}$ & -- \\
\hline
\end{tabular}

The preparation of $C$-deprotected dehydroalanine and dehydrophenylalanine derivatives requires the removal of the methyl esters. However, due to the relative ease with which catechol groups oxidize, are prone to nucleophilic attack and phenolic coupling reactions in basic media, it is not possible to remove the methyl esters from compounds 4a, 4c, 4e, 4f and 8a-g. Alternatively, the $C$-deprotected $N$-catechoyl dehydroamino acid derivatives were prepared by a sequential tert-butyloxycarbonylation and dehydration; followed by treatment with base to remove the methyl ester and cleavage of the Boc groups with TFA. Compound $\mathbf{5 b}$ was reacted with $\mathrm{Boc}_{2} \mathrm{O} / \mathrm{DMAP}$ followed by TMG to give the $O$-(tertbutyloxycarbonylated) dehydrophenylalanine derivative 7b (Scheme 5). Treatment of this compound with an aqueous solution of $\mathrm{NaOH}$ in dioxane, followed by TFA gave the $C$-deprotected $N$-catechoyl dehydrophenylalanine derivative (compound $\mathbf{9 b}$ ).

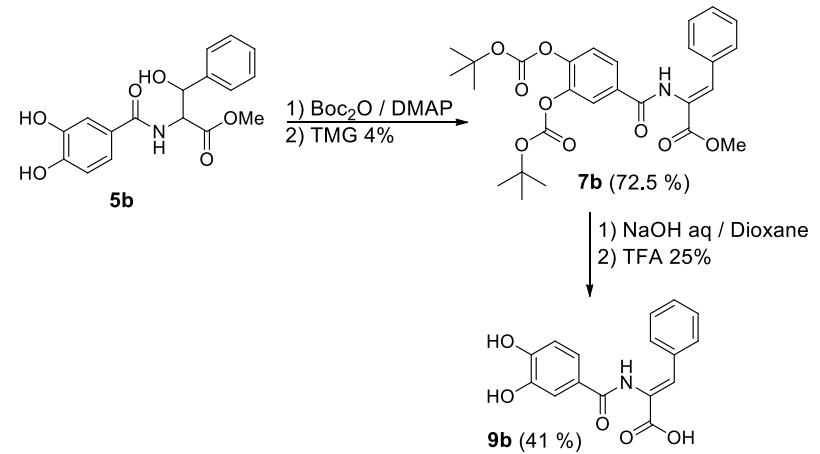

Scheme 5. Two-step procedure to prepare $C$-deprotected $N$ protocatechoyl dehydrophenylalanine.

Compounds 5e-g were also used as substrates in the same two-step procedure to give the corresponding $\mathrm{N}$ - phenoyl or $N$-catechoyl dehydrophenylalanine derivatives 9e-g (Scheme 6).<smiles>O=C(/C=C/c1ccc(O)cc1)N/C(=C\c1ccccc1)C(=O)O</smiles><smiles>O=C(/C=C/c1ccc(O)c(O)c1)N/C(=C\c1ccccc1)C(=O)O</smiles><smiles>O=C(CCc1ccc(O)c(O)c1)N/C(=C\c1ccccc1)C(=O)O</smiles>

Scheme 6. $C$-deprotected $N$-phenoyl or catechoyl dehydrophenyl-alanines.

Several alanine derivatives were also prepared by coupling phenolic and catecholic acids with the methyl ester of alanine (scheme 7). Some of these compounds were used as standards in the preliminary biological assays described below and all will be used as standards in future screening tests. 
<smiles>CC(=O)C(C)NC(=O)c1ccc(O)c(O)c1</smiles><smiles>CC(=O)OC(C)NC(=O)Cc1ccc(O)c(O)c1</smiles><smiles>CC(=O)C(C)NC(=O)/C=C/c1ccc(O)c(O)c1</smiles><smiles>CC(=O)C(C)NC(=O)CCc1ccc(O)c(O)c1</smiles>

Scheme 7. Methyl esters of $N$-phenoyl and catechoyl alanine.

The toxicity of the alanine, dehydroalanine and dehydrophenylalanine derivatives was evaluated against a panel of human cancer [gastric cancer (AGS), lung cancer (A549)] and non-cancer [lung fibroblasts (MRC5)] cell lines. All molecules were tested in a concentration range up to $25 \mu \mathrm{M}$ after $24 \mathrm{~h}$ of incubation (Figure 1).
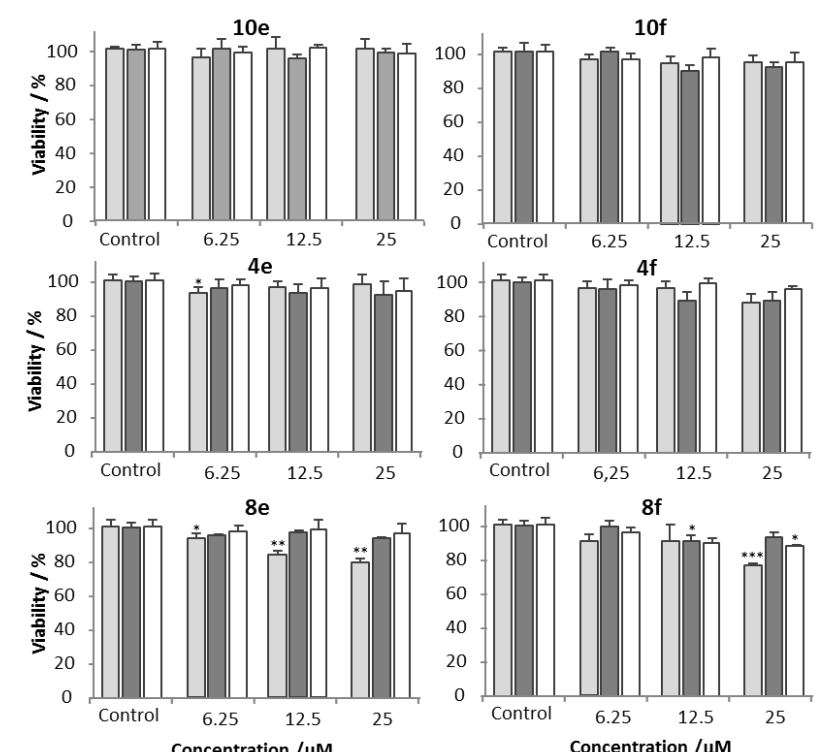

$\square$ AGS cells (human gastric cancer)

A549 cells (human non-small lung cancer)

$\square$ MRC-5 cells (human lung)

Fig. 1. Effect of the alanine, dehydroalanine and dehydrophenylalanine derivatives in the viability of AGS cells (human gastric cancer), A549 cells (human non-small lung cancer) and MRC-5 cells (human lung) after 24 hours. Statistical significance: $* p<0.05, * * p<0.01, * * * p<0.001$. Results presented as mean \pm standard deviation of the mean.

In the case of AGS cancer cells, compounds $\mathbf{1 0 e}, \mathbf{1 0 f}$, $\mathbf{4 e}$ and $\mathbf{4 f}$ where devoid of significant toxicity (Figure 1). The introduction of an aryl group in compounds $8 \mathbf{e}$ and 8f, exerted some limited toxicity at the highest concentrations tested. For example, 8e caused loss of viability around $20 \%$ at $12.5 \mu \mathrm{M}$, with $\mathbf{8 f}$ exhibiting the same effect at $25 \mu \mathrm{M}$. The higher toxicity for compound 8e and 8f may be attributed to their higher liposolubility. In the case of the A549 cell line, which is characterized as a highly aggressive phenotype with high resistance to chemotherapeutic drugs, ${ }^{55}$ the alanine, dehydroalanine and dehydrophenylalanine derivatives were either not toxic or caused only minor changes in viability. Results for the non-cancer cell line MRC-5 show that, in general, molecules displayed no toxicity in the concentration range tested.

\section{Conclusions}

A new synthetic strategy based on the tertbutyloxycarbonylation of hydroxyl groups present in serine and phenylserine derivatives $\mathrm{N}$-acylated with phenolic and catecholic acids allowed the preparation of a wide range of $N$-phenolic and $N$-catecholic dehydroalanines and dehydrophenylalanines in moderate yields. The yields were considerably improved using this methodology in a one-pot procedure. $C$-Deprotected dehydroamino derivatives were also prepared in a twostep process: the first step comprising sequential tertbutyloxycarbonylation and dehydration; followed by a sequential methyl ester cleavage with base and removal of the tert-butyloxycarbonyl groups with TFA.

These novel compounds can have important biological activities resulting from the synergic effects of both the catechol and the dehydro moieties. Preliminary assays on the toxicity of representative compounds towards two human cancer cell lines show that the most potent molecules were the dehydrophenylalanine derivatives, which can be attributed to their higher liposolubility. Assays of these compounds on cell viability against a non-cancer cell line showed that the molecules display very low or no toxicity in the concentration range tested (up to $25 \mu \mathrm{M}$ ). Thus, the toxicity of the molecules was higher towards cancer cells than non-cancer cells. These results show the impact of the chemical structure upon potency and tropism towards cancer cells. This information will be useful for further modification of these molecules, aiming to increase their bioactivity. They also indicate that these molecules are excellent candidates for incorporation into peptide-based hydrogels with potential in various bioengineering applications such as drug delivery.

\section{Experimental Section}

\subsection{General methods}

Melting points $\left({ }^{\circ} \mathrm{C}\right)$ were determined in a Gallenkamp apparatus and are uncorrected. ${ }^{1} \mathrm{H}$ and ${ }^{13} \mathrm{C}$ NMR spectra were recorded on a Bruker Avance $\mathrm{II}^{+}$at 400 and $100.6 \mathrm{MHz}$, respectively. ${ }^{1} \mathrm{H}-{ }^{1} \mathrm{H}$ spin-spin decoupling, DEPT $\theta 45^{\circ}$, HMQC and HMBC were used to attribute some signals. Chemical shifts are given in ppm and coupling constants in Hz. HRMS data were recorded by the Laboratory for Structural Elucidation of the Materials Centre of the University of Porto on an LTQ Orbitrap ${ }^{\mathrm{TM}}$ XL hybrid mass spectrometer (Thermo Fischer Scientific, Bremen, Germany) controlled by $L T Q$ 
Tune Plus 2.5.5 and Xcalibur 2.1.0. The reactions were monitored by thin layer chromatography (TLC). Column chromatography was performed on Macherey-Nagel silica gel 230-400 mesh. Petroleum ether refers to the boiling range $40-60{ }^{\circ} \mathrm{C}$. Solvents were used without purification except for acetonitrile which was dried using standard procedures.

4.1.1. Cell culture. Human gastric carcinoma cell line AGS and human lung carninoma cell line A549 were from Sigma-Aldrich, St. Louis, MO, USA, and human lung fibroblast cell line MRC-5 was from ECACC, Porton Down Salisbury, UK. Cells were cultured as monolayer at $37{ }^{\circ} \mathrm{C}$ in a humidified incubator with $5 \%$ carbon dioxide. AGS were grown in glutamine-enriched Dulbecco's Modified Eagle Medium (DMEM), supplemented with $1 \%$ streptomycin/penicillin and $10 \%$ fetal bovine serum (Gibcoß), while A549 and MRC-5 cells were grown in DMEM/F-12, supplemented with $1 \%$ streptomycin/ penicillin and $10 \%$ fetal bovine serum. For subculture, cells were washed with Hank's buffered salt solution (HBSS), treated with $0.25 \%$ Trypsin-EDTA solution (Sigma, St. Louis, MO) for $3 \mathrm{~min}$ at $37{ }^{\circ} \mathrm{C}$, resuspended in $5 \mathrm{~mL}$ of culture medium and centrifuged at $390 \mathrm{~g}$ for $4 \mathrm{~min}$. The supernatant was removed and the cell pellet was resuspended in culture medium.

4.1.2. Cell viability. The MTT assay was conducted as described before. ${ }^{53}$ Cells were plated at a density of $1,5 \times 10^{4}$ cells/well for AGS, $1 \times 10^{4}$ cells/well for A549 and $2.5 \times 10^{4}$ cells/well for MRC-5 and allowed to attach for 24 hours. Cells were exposed to the molecules under study in a concentration $\mathrm{n}$ range up to $25 \mu \mathrm{M}$ range, for 24 hours. After this period, the medium was replaced by $100 \mu \mathrm{L}$ of $0.5 \mathrm{mg} / \mathrm{mL}$ MTT solution and incubated for 2 hours. The formazan in each well was then dissolved in $200 \mu \mathrm{L}$ of a solution of 3:1 DMSO:isopropanol. Finally, the absorbance at $560 \mathrm{~nm}$ was read in a Thermo Scientific $^{\mathrm{TM}}$ Multiskan ${ }^{\mathrm{TM}} \mathrm{GO}$ microplate reader.

All determinations were performed in duplicate and the results were confirmed in three independent assays.

\subsection{Synthesis}

4.2.1. Synthesis of the methyl esters of $N$-phenoyl and $N$ catechoyl serine, phenylserine and alanine

General procedure for the synthesis of the methyl esters of $N$-phenoyl and N-catechoyl serine, phenylserine and alanine

To a solution of the phenolic or catecholic acid in acetonitrile $\left(0.0100 \mathrm{~mol} \mathrm{dm}^{-3}\right), 1.1$ equiv. of HOBt was added, followed by 1.1 equiv. of HBTU, 1.1 equiv. of the methyl ester of the amino acid hydrochloride and 2.2 equiv. of $\mathrm{NEt}_{3}$ in an ice bath. After stirring for 4 hours at room temperature, the solvent was evaporated at reduced pressure. The residue was dissolved in ethyl acetate $\left(100 \mathrm{~cm}^{3}\right)$ and washed with $\mathrm{KHSO}_{4}\left(1 \mathrm{~mol} \mathrm{dm}^{-3}\right), \mathrm{NaHCO}_{3}\left(1 \mathrm{~mol} \mathrm{dm}^{-3}\right)$ and brine (3 times $25 \mathrm{~cm}^{3}$ each). The organic layer was dried with $\mathrm{MgSO}_{4}$ and the solvent evaporated at reduced pressure.
4.2.1.1. Synthesis of 4-hydroxybenzoyl-L-Ser-OMe, (1a) The general procedure described above was followed with 4-hydroxybenzoic acid $(0.345 \mathrm{~g}, 2.500 \mathrm{mmol})$ and $\mathrm{HCl} . \mathrm{H}-\mathrm{L}-\mathrm{Ser}-\mathrm{OMe}$ to give compound 1a $(0.425 \mathrm{~g}$, $71.0 \%)$ as a colourless oil. ${ }^{1} \mathrm{H}$ NMR $(400 \mathrm{MHz}$, $\left.\mathrm{CD}_{3} \mathrm{OCD}_{3}\right): \delta=3.74\left(\mathrm{~s}, 3 \mathrm{H}, \mathrm{COOCH}_{3}\right), 3.95(\mathrm{dd}, J=4.4$ $\left.\mathrm{Hz}, J=11.2 \mathrm{~Hz}, 1 \mathrm{H}, \beta \mathrm{CH}_{2}\right), 4.02(\mathrm{dd}, J=4.4 \mathrm{~Hz}, J=$ $\left.11.2 \mathrm{~Hz}, 1 \mathrm{H}, \beta \mathrm{CH}_{2}\right), 4.73-4.77(\mathrm{~m}, 1 \mathrm{H}, \alpha \mathrm{CH}), 6.93(\mathrm{~d}, J$ $=8.8 \mathrm{~Hz}, 2 \mathrm{H}, \mathrm{ArH}$ ), 7.59 (br. d, $J=7.6 \mathrm{~Hz}, 1 \mathrm{H}, \mathrm{NH}$ ), $7.85(\mathrm{~d}, J=8.8 \mathrm{~Hz}, 2 \mathrm{H}, \mathrm{ArH}), 9.01$ (br. s, $1 \mathrm{H}, \mathrm{OH})$ ppm. ${ }^{13} \mathrm{C}$ NMR (100.6 MHz, $\left.\mathrm{CD}_{3} \mathrm{OCD}_{3}\right): \delta=52.30$ $\left(\mathrm{CO}_{2} \mathrm{CH}_{3}\right), 56.13(\alpha \mathrm{CH}), 62.90\left(\beta_{\mathrm{CH}_{2}}\right), 115.74(2 \mathrm{CH})$, $126.26(\mathrm{C}), 130.13(2 \mathrm{CH}), 161.29(\mathrm{C}), 167.07(\mathrm{C}=\mathrm{O})$, $171.92(\mathrm{C}=\mathrm{O}) \mathrm{ppm} . \mathrm{m} / \mathrm{z}$ (HRESI-MS) 240.08674, ([M + $\mathrm{H}]^{+}, \mathrm{C}_{11} \mathrm{H}_{14} \mathrm{NO}_{5}$, requires 240.08720).

4.2.1.2. Synthesis of 2-(4-hydroxyphenyl)acetoyl-L-SerOMe, (1c) The general procedure described above was followed with 2-(4-hydroxyphenyl)acetic acid $(0.380 \mathrm{~g}$, $2.500 \mathrm{mmol})$ and $\mathrm{HCl} . \mathrm{H}-\mathrm{L}-\mathrm{Ser}-\mathrm{OMe}$ to give compound 1c $(0.330 \mathrm{~g}, 52.2 \%)$ as a colourless oil that solidified on standing. M.p. 64.0-65.0 ${ }^{\circ} \mathrm{C} .{ }^{1} \mathrm{H}$ NMR $(400 \mathrm{MHz}$, $\left.\mathrm{CD}_{3} \mathrm{OCD}_{3}\right): \delta=3.53\left(\mathrm{~s}, 2 \mathrm{H}, \mathrm{CH}_{2}\right), 3.69(\mathrm{~s}, 3 \mathrm{H}$, $\left.\mathrm{COOCH}_{3}\right), 3.78\left(\mathrm{dd}, J=4.0 \mathrm{~Hz}, J=11.2 \mathrm{~Hz}, 1 \mathrm{H}, \beta \mathrm{CH}_{2}\right)$, 3.92 (dd, $J=4.0 \mathrm{~Hz}, J=11.2 \mathrm{~Hz}, 1 \mathrm{H}, \beta \mathrm{CH}_{2}$ ), 4.25 (br. s, $1 \mathrm{H}, \mathrm{OH}$ Ser), 4.52-4.57 (m, 1H, $\alpha \mathrm{CH}), 6.80(\mathrm{~d}, J=8.8$ $\mathrm{Hz}, 2 \mathrm{H}, \mathrm{ArH}$ ), 7.19 (d, $J=8.8 \mathrm{~Hz}, 2 \mathrm{H}, \mathrm{ArH}$ ), 7.25 (br. s, $1 \mathrm{H}, \mathrm{OH}$ ), 8.30 (br. s, $1 \mathrm{H}, \mathrm{NH}$ ) ppm. ${ }^{13} \mathrm{C}$ NMR (100.6 $\left.\mathrm{MHz}, \mathrm{CD}_{3} \mathrm{OCD}_{3}\right): \delta=42.48\left(\mathrm{CH}_{2}\right), 52.25\left(\mathrm{CO}_{2} \mathrm{CH}_{3}\right)$, $55.54(\alpha \mathrm{CH}), 62.83\left(\beta_{2}\right), 115.93(\mathrm{CH}), 122.25(\mathrm{CH})$, $127.44(\mathrm{C}), 131.12(2 \mathrm{CH}), 156.99(\mathrm{C}), 171.69(\mathrm{C}=\mathrm{O})$, $171.76(\mathrm{C}=\mathrm{O}) \mathrm{ppm} . \mathrm{m} / \mathrm{z}$ (HRESI-MS) 254.10235, ([M + $\mathrm{H}]^{+}, \mathrm{C}_{12} \mathrm{H}_{16} \mathrm{NO}_{5}$, requires 254.10285).

4.2.1.3. Synthesis of p-coumaroyl-L-Ser-OMe, (1e) The general procedure described above was followed with $p$ coumaric acid $(0.410 \mathrm{~g}, 2.500 \mathrm{mmol})$ and HCl.H-L-SerOMe to give compound 1e $(0.374 \mathrm{~g}, 56.6 \%)$ as a light yellow oil. ${ }^{1} \mathrm{H}$ NMR $\left(400 \mathrm{MHz}, \mathrm{CD}_{3} \mathrm{OCD}_{3}\right): \delta=3.73(\mathrm{~s}$, $\left.3 \mathrm{H}, \mathrm{COOCH}_{3}\right), 3.87(\mathrm{dd}, J=4.0 \mathrm{~Hz}, J=11.2 \mathrm{~Hz}, 1 \mathrm{H}$, $\left.\beta \mathrm{CH}_{2}\right), 3.98\left(\mathrm{dd}, J=4.0 \mathrm{~Hz}, J=11.2 \mathrm{~Hz}, 1 \mathrm{H}, \beta \mathrm{CH}_{2}\right)$, $4.70(\mathrm{t}, J=4.0 \mathrm{~Hz}, 1 \mathrm{H}, \alpha \mathrm{CH}), 6.73(\mathrm{~d}, J=15.6 \mathrm{~Hz}, 1 \mathrm{H}$, $\mathrm{Ar}-\mathrm{CH}=\mathrm{CH}-), 6.90(\mathrm{~d}, J=8.8 \mathrm{~Hz}, 2 \mathrm{H}, \mathrm{ArH}), 7.48-7.54$ (m, 3H, $\mathrm{ArH}+\mathrm{Ar}-\mathrm{CH}=\mathrm{CH}-)$ ppm. ${ }^{13} \mathrm{C}$ NMR (100.6 $\left.\mathrm{MHz}, \mathrm{CD}_{3} \mathrm{OCD}_{3}\right): \delta=52.27\left(\mathrm{CO}_{2} \mathrm{CH}_{3}\right), 55.63(\alpha \mathrm{CH})$, $63.05\left(\beta^{2} \mathrm{CH}_{2}\right), 116.49(2 \mathrm{CH}), 119.03(\mathrm{CH}), 127.67(\mathrm{C})$, $130.26(2 \mathrm{CH}), 140.96(\mathrm{CH}), 159.74(\mathrm{C}), 166.38(\mathrm{C}=\mathrm{O})$, $171.83(\mathrm{C}=\mathrm{O}) \mathrm{ppm} . \mathrm{m} / \mathrm{z}$ (HRESI-MS) 266.10202, ([M + $\mathrm{H}]^{+}, \mathrm{C}_{13} \mathrm{H}_{16} \mathrm{NO}_{5}$, requires 266.10285).

4.2.1.4. Synthesis of caffeoyl-L-Ser-OMe, (1f) The general procedure described above was followed with caffeic acid $(0.450 \mathrm{~g}, 2.500 \mathrm{mmol})$ and HCl.H-L-Ser$\mathrm{OMe}$ to give compound 1f $(0.495 \mathrm{~g}, 70.5 \%)$ as a colourless oil. ${ }^{1} \mathrm{H}$ NMR $\left(400 \mathrm{MHz}, \mathrm{CD}_{3} \mathrm{OCD}_{3}\right): \delta=3.73$ $\left(\mathrm{s}, 3 \mathrm{H}, \mathrm{COOCH}_{3}\right), 3.88(\mathrm{dd}, J=4.0 \mathrm{~Hz}, J=10.8 \mathrm{~Hz}, 1 \mathrm{H}$, $\beta C H), 3.99$ (dd, $J=4.0 \mathrm{~Hz}, J=10.8 \mathrm{~Hz}, 1 \mathrm{H}, \beta \mathrm{CH}), 4.70-$ $4.74(\mathrm{~m}, 1 \mathrm{H}, \alpha \mathrm{CH}), 6.69(\mathrm{~d}, J=15.6 \mathrm{~Hz}, 1 \mathrm{H}$, Ar$\mathrm{CH}=\mathrm{CH}-)$, 6.85-6.88 (m, 1H, ArH), 6.94-7.00 (m, 1H, ArH), 7.13 (d, $J=2.0 \mathrm{~Hz}, 1 \mathrm{H}, \mathrm{ArH}), 7.47(\mathrm{~d}, J=15.6$ $\mathrm{Hz}, 1 \mathrm{H}, \mathrm{Ar}-\mathrm{CH}=\mathrm{CH}-$ ), 8.37 (br. s, $1 \mathrm{H}, \mathrm{NH}$ ) ppm. ${ }^{13} \mathrm{C}$ NMR (100.6 MHz, $\left.\mathrm{CD}_{3} \mathrm{OCD}_{3}\right): \delta=52.32\left(\mathrm{CO}_{2} \mathrm{CH}_{3}\right)$, $55.64(\alpha \mathrm{CH}), 63.06\left(\beta \mathrm{CH}_{2}\right), 114.84(\mathrm{CH}), 116.26(\mathrm{CH})$, $118.92(\mathrm{CH}), 118.97(\mathrm{CH}), 121.77(\mathrm{CH}), 128.26(\mathrm{C})$, $141.52(\mathrm{CH}), 146.13(\mathrm{C}), 147.87(\mathrm{C}), 166.69(\mathrm{C}=\mathrm{O})$, 
$171.79(\mathrm{C}=\mathrm{O}) \mathrm{ppm} . \mathrm{m} / \mathrm{z}$ (HRESI-MS) 282.09683, $([\mathrm{M}+$ $\mathrm{H}]^{+}, \mathrm{C}_{13} \mathrm{H}_{16} \mathrm{NO}_{6}$, requires 282.09776).

4.2.1.5. Synthesis of 4-hydroxybenzoyl-D,L-Phe( $\beta-O H)$ $O M e,(5 a)$ The general procedure described above was followed with 4-hydroxybenzoic acid $(0.345 \mathrm{~g}$, $2.500 \mathrm{mmol})$ and $\mathrm{HCl} . \mathrm{H}-D, L-\mathrm{Phe}(\beta-\mathrm{OH})-\mathrm{OMe}$ to give compound 5a $(0.758 \mathrm{~g}, 96.2 \%)$ as a colourless oil. ${ }^{1} \mathrm{H}$ NMR $\left(400 \mathrm{MHz}, \mathrm{CD}_{3} \mathrm{OCD}_{3}\right): \delta=3.72(\mathrm{~s}, 3 \mathrm{H}$, $\left.\mathrm{COOCH}_{3}\right), 4.96(\mathrm{dd}, J=3.6 \mathrm{~Hz}, J=8.8 \mathrm{~Hz}, 1 \mathrm{H}, \alpha \mathrm{CH})$, 5.22 (br. s, $1 \mathrm{H}, \mathrm{OH}), 5.42$ (br. s, $1 \mathrm{H}, \beta \mathrm{CH}), 6.89$ (d, $J=$ $8.8 \mathrm{~Hz}, 2 \mathrm{H}, \mathrm{ArH}), 7.24-7.36(\mathrm{~m}, 3 \mathrm{H}, \mathrm{ArH}), 7.51(\mathrm{~d}, J=$ $8.4 \mathrm{~Hz}, 2 \mathrm{H}, \mathrm{ArH}), 7.75(\mathrm{~d}, J=8.8 \mathrm{~Hz}, 2 \mathrm{H}, \mathrm{ArH}), 8.96$ (br. s, $1 \mathrm{H}, \mathrm{NH})$ ppm. $\left.{ }^{13} \mathrm{C} \mathrm{NMR} \mathrm{(100.6} \mathrm{MHz,} \mathrm{CD}_{3} \mathrm{OCD}_{3}\right)$ : $\delta=52.37\left(\mathrm{CO}_{2} \mathrm{CH}_{3}\right), 59.98(\alpha \mathrm{CH}), 73.80(\beta \mathrm{CH}), 115.78$ $(\mathrm{CH}), 126.21(\mathrm{C}), 126.87(2 \mathrm{CH}), 128.16(\mathrm{CH}), 128.81$ $(2 \mathrm{CH}), 130.04(2 \mathrm{CH}), 134.10(\mathrm{CH}), 142.47(\mathrm{C}), 161.33$ (C), $167.29(\mathrm{C}=\mathrm{O}), 171.65(\mathrm{C}=\mathrm{O}) \mathrm{ppm} . \mathrm{m} / \mathrm{z}$ (HRESIMS) 316.11787, $\left([\mathrm{M}+\mathrm{H}]^{+}, \quad \mathrm{C}_{17} \mathrm{H}_{18} \mathrm{NO}_{5}\right.$, requires 316.11850).

4.2.1.6. Synthesis of protocatechoyl-D,L-Phe( $\beta-O H)$ $O M e,(5 \boldsymbol{b})$ The general procedure described above was followed with protocatechuic acid $(0.385 \mathrm{~g}, 2.500 \mathrm{mmol})$ and $\mathrm{HCl} . \mathrm{H}-D, L-\mathrm{Phe}(\beta-\mathrm{OH})-\mathrm{OMe}$ to give compound $\mathbf{5 b}$ $(0.712 \mathrm{~g}, 86.0 \%)$ as a white solid. (from ethyl acetate/petroleum ether). M.p. 164.0-165.0 ${ }^{\circ} \mathrm{C} .{ }^{1} \mathrm{H}$ NMR $\left(400 \mathrm{MHz}, \mathrm{CD}_{3} \mathrm{OCD}_{3}\right): \delta=3.72\left(\mathrm{~s}, 3 \mathrm{H}, \mathrm{COOCH}_{3}\right), 4.92-$ $4.95(\mathrm{~m}, 1 \mathrm{H}, \alpha \mathrm{CH}), 5.41(\mathrm{~d}, J=3.2 \mathrm{~Hz}, 1 \mathrm{H}, \beta \mathrm{CH}), 6.88$ $(\mathrm{d}, J=8.0 \mathrm{~Hz}, 1 \mathrm{H}, \mathrm{ArH}), 7.22-7.36(\mathrm{~m}, 5 \mathrm{H}, \mathrm{ArH}), 7.50-$ $7.52(\mathrm{~m}, 2 \mathrm{H}, \mathrm{ArH})$ ppm. ${ }^{13} \mathrm{C}$ NMR $(100.6 \mathrm{MHz}$, $\left.\mathrm{CD}_{3} \mathrm{OCD}_{3}\right): \delta=52.37\left(\mathrm{CO}_{2} \mathrm{CH}_{3}\right), 59.86(\alpha \mathrm{CH}), 73.74$ $(\beta \mathrm{CH}), 115.43(\mathrm{CH}), 115.56(\mathrm{CH}), 120.36(\mathrm{CH}), 126.88$ $(2 \mathrm{CH}), 128.18(\mathrm{CH}), 128.84(2 \mathrm{CH}), 142.49(\mathrm{C}), 145.56$ (C), 149.24 (C), 167.17 (C), 170.89 (C=O), 171.66 $(\mathrm{C}=\mathrm{O}) \mathrm{ppm} . \mathrm{m} / \mathrm{z}\left(\right.$ HRESI-MS) 332.11256, $\left([\mathrm{M}+\mathrm{H}]^{+}\right.$, $\mathrm{C}_{17} \mathrm{H}_{18} \mathrm{NO}_{6}$, requires 332.11341).

4.2.1.7. Synthesis of 2-(4-hydroxyphenyl)acetoyl-D,LPhe $(\beta-O H)-O M e,(5 \mathrm{c})$ The general procedure described above was followed with 2-(4-hydroxyphenyl)acetic acid $(0.380 \mathrm{~g}, 2.500 \mathrm{mmol})$ and $\mathrm{HCl} . \mathrm{H}-D, L-\mathrm{Phe}(\beta-\mathrm{OH})-\mathrm{OMe}$ to give compound $\mathbf{5 c}(0.735 \mathrm{~g}, 89.3 \%)$ as a light yellow oil. ${ }^{1} \mathrm{H}$ NMR (400 MHz, $\left.\mathrm{CD}_{3} \mathrm{OCD}_{3}\right): \delta=3.42(\mathrm{~d}, J=8.8$ $\left.\mathrm{Hz}, 2 \mathrm{H}, \mathrm{CH}_{2}\right), 3.70\left(\mathrm{~s}, 3 \mathrm{H}, \mathrm{COOCH}_{3}\right), 4.72-4.75(\mathrm{~m}, 1 \mathrm{H}$, $\alpha \mathrm{CH}), 5.31(\mathrm{~d}, J=2.8 \mathrm{~Hz}, 1 \mathrm{H}, \beta \mathrm{CH}), 6.77(\mathrm{~d}, J=8.4$ $\mathrm{Hz}, 2 \mathrm{H}, \mathrm{ArH}), 7.02$ (d, $J=8.4 \mathrm{~Hz}, 2 \mathrm{H}, \mathrm{ArH}), 7.26-7.38$ (m, 5H, ArH), 8.31 (br. s, $1 \mathrm{H}, \mathrm{NH}$ ) ppm. ${ }^{13} \mathrm{C} \mathrm{NMR}$ $\left(100.6 \mathrm{MHz}, \mathrm{CD}_{3} \mathrm{OCD}_{3}\right): \delta=42.42\left(\mathrm{CH}_{2}\right), 52.32$ $\left(\mathrm{CO}_{2} \mathrm{CH}_{3}\right), 59.27(\alpha \mathrm{CH}), 73.43(\beta \mathrm{CH}), 115.93(\mathrm{CH})$, $126.89(2 \mathrm{CH}), 127.25(\mathrm{C}), 128.08(\mathrm{CH}), 128.72(2 \mathrm{CH})$, $131.13(2 \mathrm{CH}), 142.27(\mathrm{C}), 156.96(\mathrm{C}), 171.42(\mathrm{C}=\mathrm{O})$, $171.72(\mathrm{C}=\mathrm{O}) \mathrm{ppm} . \mathrm{m} / \mathrm{z}$ (HRESI-MS) 330.13331, ([M + $\mathrm{H}]^{+}, \mathrm{C}_{18} \mathrm{H}_{20} \mathrm{NO}_{5}$, requires 330.13415).

4.2.1.8. Synthesis of 2-(3,4-dihydroxyphenyl)acetoyl$D, L-P h e(\beta-O H)-O M e, \quad(5 d)$ The general procedure described above was followed with 2-(3,4dihydroxyphenyl)acetic acid $(0.420 \mathrm{~g}, 2.500 \mathrm{mmol})$ and $\mathrm{HCl} . \mathrm{H}-D, L-\mathrm{Phe}(\beta-\mathrm{OH})-\mathrm{OMe}$ to give compound $\mathbf{5 d}$ $(0.739 \mathrm{~g}, 85.6 \%)$ as a light yellow oil. ${ }^{1} \mathrm{H}$ NMR (400 $\left.\mathrm{MHz}, \mathrm{CD}_{3} \mathrm{OCD}_{3}\right): \delta=3.37\left(\mathrm{~d}, J=6.0 \mathrm{~Hz}, 2 \mathrm{H}, \mathrm{CH}_{2}\right)$, $3.69\left(\mathrm{~s}, 3 \mathrm{H}, \mathrm{COOCH}_{3}\right), 4.69-4.72(\mathrm{~m}, 1 \mathrm{H}, \alpha \mathrm{CH}), 5.28(\mathrm{~d}$, $J=2.8 \mathrm{~Hz}, 1 \mathrm{H}, \beta \mathrm{CH}), 6.55(\mathrm{dd}, J=2.0 \mathrm{~Hz}, J=8.0 \mathrm{~Hz}$, $1 \mathrm{H}, \operatorname{ArH}), 6.75(\mathrm{~d}, J=2.0 \mathrm{~Hz}, 1 \mathrm{H}, \operatorname{ArH}), 6.77(\mathrm{~d}, J=8.0$ $\mathrm{Hz}, 1 \mathrm{H}, \mathrm{ArH}), 7.22-7.36$ (m, 5H, ArH), 7.91 (br. s, 1H,
$\mathrm{NH})$ ppm. ${ }^{13} \mathrm{C}$ NMR $\left(100.6 \mathrm{MHz}, \mathrm{CD}_{3} \mathrm{OCD}_{3}\right): \delta=42.74$ $\left(\mathrm{CH}_{2}\right), 52.33\left(\mathrm{CO}_{2} \mathrm{CH}_{3}\right), 59.29(\alpha \mathrm{CH}), 73.49(\beta \mathrm{CH})$, $115.96(\mathrm{CH}), 117.31(\mathrm{CH}), 121.55(\mathrm{CH}), 126.90(2 \mathrm{CH})$, $127.89(\mathrm{C}), 128.12(\mathrm{CH}), 128.72(2 \mathrm{CH}), 142.20(\mathrm{C})$, 144.71 (C), 145.73 (C), $171.67(\mathrm{C}=\mathrm{O}), 171.74(\mathrm{C}=\mathrm{O})$ ppm. $\mathrm{m} / \mathrm{z}$ (HRESI-MS) 346.12851, $\left([\mathrm{M}+\mathrm{H}]^{+}\right.$, $\mathrm{C}_{18} \mathrm{H}_{20} \mathrm{NO}_{6}$, requires 346.12906).

4.2.1.9. Synthesis of p-coumaroyl-D,L-Phe( $\beta$-OH)-OMe, (5e) The general procedure described above was followed with $p$-coumaric acid $(0.410 \mathrm{~g}, 2.500 \mathrm{mmol})$ and $\mathrm{HCl} . \mathrm{H}-D, L-\mathrm{Phe}(\beta-\mathrm{OH})-\mathrm{OMe}$ to give compound $\mathbf{5 e}$ $(0.680 \mathrm{~g}, 79.8 \%)$ as a as a yellow oil. ${ }^{1} \mathrm{H}$ NMR (400 $\left.\mathrm{MHz}, \mathrm{CD}_{3} \mathrm{OCD}_{3}\right): \delta=3.71\left(\mathrm{~s}, 3 \mathrm{H}, \mathrm{COOCH}_{3}\right), 4.93(\mathrm{~d}, J$ $=3.2 \mathrm{~Hz}, 1 \mathrm{H}, \alpha \mathrm{CH}), 5.35(\mathrm{~d}, J=3.2 \mathrm{~Hz}, 1 \mathrm{H}, \beta \mathrm{CH}), 6.74$ $(\mathrm{d}, J=15.6 \mathrm{~Hz}, 1 \mathrm{H}, \mathrm{Ar}-\mathrm{CH}=\mathrm{CH}-), 6.87(\mathrm{~d}, J=8.4 \mathrm{~Hz}$, 2H, ArH), 7.22-7.26 (m, 1H, ArH), 7.30-7.35 (m, 2H, ArH), 7.38 (d, $J=15.6 \mathrm{~Hz}, 1 \mathrm{H}, \mathrm{Ar}-\mathrm{CH}=\mathrm{CH}-), 7.42(\mathrm{~d}, J$ $=8.4 \mathrm{~Hz}, 2 \mathrm{H}, \mathrm{ArH}), 7.44-7.47(\mathrm{~m}, 2 \mathrm{H}, \mathrm{ArH}) \mathrm{ppm} .{ }^{13} \mathrm{C}$ NMR (100.6 MHz, $\left.\mathrm{CD}_{3} \mathrm{OCD}_{3}\right): \delta=52.37\left(\mathrm{CO}_{2} \mathrm{CH}_{3}\right)$, $59.56(\alpha \mathrm{CH}), 73.66(\beta \mathrm{CH}), 116.46(2 \mathrm{CH}), 118.70(\mathrm{CH})$, $126.92(2 \mathrm{CH}), 127.49(\mathrm{C}), 128.13(\mathrm{CH}), 128.74(2 \mathrm{CH})$, $130.24(2 \mathrm{CH}), 141.14(\mathrm{CH}), 142.39(\mathrm{C}), 159.79(\mathrm{C})$, $166.91(\mathrm{C}=\mathrm{O}), 171.60 \quad(\mathrm{C}=\mathrm{O}) \mathrm{ppm} . \mathrm{m} / \mathrm{z}$ (HRESI-MS) 342.13374, $\left([\mathrm{M}+\mathrm{H}]^{+}, \mathrm{C}_{19} \mathrm{H}_{20} \mathrm{NO}_{5}\right.$, requires 342.13415).

4.2.1.10. Synthesis of caffeoyl-D,L-Phe $(\beta-O H)-O M e,(5 f)$ The general procedure described above was followed with cafeic acid $(0.450 \mathrm{~g}, 2.500 \mathrm{mmol})$ and HCl.H-D,L$\mathrm{Phe}(\beta-\mathrm{OH})-\mathrm{OMe}$ to give compound $\mathbf{5 f}(0.867 \mathrm{~g}, 97.1 \%)$ as a light yellow solid. (from ethyl acetate/petroleum ether). M.p. $182.0-183.0{ }^{\circ} \mathrm{C} .{ }^{1} \mathrm{H}$ NMR $(400 \mathrm{MHz}$, $\left.\mathrm{CD}_{3} \mathrm{OCD}_{3}\right): \delta=3.71\left(\mathrm{~s}, 3 \mathrm{H}, \mathrm{COOCH}_{3}\right), 4.90-4.93(\mathrm{~m}$, $1 \mathrm{H}, \alpha \mathrm{CH}), 5.37(\mathrm{~d}, J=3.2 \mathrm{~Hz}, 1 \mathrm{H}, \beta \mathrm{CH}), 6.69(\mathrm{~d}, J=$ $15.6 \mathrm{~Hz}, 1 \mathrm{H}, \mathrm{Ar}-\mathrm{CH}=\mathrm{CH}-), 6.85(\mathrm{~d}, J=8.4 \mathrm{~Hz}, 1 \mathrm{H}$, ArH), $6.96(\mathrm{dd}, J=2.0 \mathrm{~Hz}, J=8.4 \mathrm{~Hz}, 1 \mathrm{H}, \mathrm{ArH}), 7.10$ $(\mathrm{d}, J=2.0 \mathrm{~Hz}, 1 \mathrm{H}, \mathrm{ArH}), 7.22-7.26(\mathrm{~m}, 1 \mathrm{H}, \mathrm{ArH}), 7.31-$ $7.36(\mathrm{~m}, 3 \mathrm{H}, \mathrm{ArH}+\mathrm{Ar}-\mathrm{CH}=\mathrm{CH}-), 7.47-7.50(\mathrm{~m}, 2 \mathrm{H}$, $\mathrm{ArH}) \mathrm{ppm} .{ }^{13} \mathrm{C} \mathrm{NMR}\left(100.6 \mathrm{MHz}, \mathrm{CD}_{3} \mathrm{OCD}_{3}\right): \delta=52.33$ $\left(\mathrm{CO}_{2} \mathrm{CH}_{3}\right), 59.55(\alpha \mathrm{CH}), 73.76(\beta \mathrm{CH}), 114.88(\mathrm{CH})$, $116.21(\mathrm{CH}), 118.99(\mathrm{CH}), 121.68(\mathrm{CH}), 126.96(2 \mathrm{CH})$, $128.14(\mathrm{CH}), 128.31(\mathrm{C}), 128.75(2 \mathrm{CH}), 141.34(\mathrm{CH})$, 142.49 (C), 146.11 (C), 147.82 (C), 166.68 (C=O), $171.64(\mathrm{C}=\mathrm{O}) \mathrm{ppm} . \mathrm{m} / \mathrm{z}$ (HRESI-MS) 358.12837, ([M + $\mathrm{H}]^{+}, \mathrm{C}_{19} \mathrm{H}_{20} \mathrm{NO}_{6}$, requires 358.12906).

4.2.1.11. Synthesis of hydrocaffeoyl-D,L-Phe( $\beta-O H)$ $O M e,(5 \mathrm{~g})$ The general procedure described above was followed with hydrocaffeic acid $(0.455 \mathrm{~g}, 2.500 \mathrm{mmol})$ and $\mathrm{HCl} . \mathrm{H}-D, L-\mathrm{Phe}(\beta-\mathrm{OH})-\mathrm{OMe}$ to give compound $\mathbf{5 g}$ (0.803 g, 89.4\%) as a white solid. (from ethyl acetate). M.p. $174.0-175.0 \quad{ }^{\circ} \mathrm{C} .{ }^{1} \mathrm{H}$ NMR (400 MHz, $\left.\mathrm{CD}_{3} \mathrm{OD}\right): \delta=2.41-2.44\left(\mathrm{~m}, 2 \mathrm{H}, \mathrm{CH}_{2}\right), 2.59-2.61(\mathrm{~m}, 2 \mathrm{H}$, $\left.\mathrm{CH}_{2}\right), 3.72\left(\mathrm{~s}, 3 \mathrm{H}, \mathrm{OCH}_{3}\right), 4.77(\mathrm{~d}, J=3.6 \mathrm{~Hz}, 1 \mathrm{H}$, $\alpha \mathrm{CH}), 5.24(\mathrm{~d}, J=3.6 \mathrm{~Hz}, 1 \mathrm{H}, \beta \mathrm{CH}), 6.45(\mathrm{dd}, J=2.0$ $\mathrm{Hz}, J=8.0 \mathrm{~Hz}, 1 \mathrm{H}, \mathrm{ArH}), 6.60(\mathrm{~d}, J=2.0 \mathrm{~Hz}, 1 \mathrm{H}, \mathrm{ArH})$, $6.65(\mathrm{~d}, J=8.0 \mathrm{~Hz}, 1 \mathrm{H}, \mathrm{ArH}), 7.24-7.39(\mathrm{~m}, 5 \mathrm{H}, \mathrm{ArH})$ ppm. ${ }^{13} \mathrm{C}$ NMR (100.6 MHz, $\left.\mathrm{CD}_{3} \mathrm{OCD}_{3}\right): \delta=32.14$ $\left(\mathrm{CH}_{2}\right), 38.85\left(\mathrm{CH}_{2}\right), 52.79\left(\mathrm{OCH}_{3}\right), 59.99(\alpha \mathrm{CH}), 74.10$ $(\beta \mathrm{CH}), 116.33(\mathrm{CH}), 116.41(\mathrm{CH}), 120.45(\mathrm{CH}), 127.19$ $(2 \mathrm{CH}), 128.66(\mathrm{CH}), 129.16(2 \mathrm{CH}), 133.73(\mathrm{C}), 142.28$ (C), 144.55 (C), 14.16 (C), $1702.31(\mathrm{C}=\mathrm{O}), 175.64$ $(\mathrm{C}=\mathrm{O}) \mathrm{ppm} . \mathrm{m} / \mathrm{z}$ (HRESI-MS) 360.14382, $\left([\mathrm{M}+\mathrm{H}]^{+}\right.$, $\mathrm{C}_{19} \mathrm{H}_{22} \mathrm{NO}_{6}$, requires 360.14471). 
4.2.1.12. Synthesis of galloyl-D,L-Phe( $\beta-O H)-O M e,(5 h)$ The general procedure described above was followed with gallic acid $(0.425 \mathrm{~g}, 2.500 \mathrm{mmol})$ and $\mathrm{HCl} . \mathrm{H}-\mathrm{D}, \mathrm{L}-$ $\mathrm{Phe}(\beta-\mathrm{OH})-\mathrm{OMe}$ to give compound $\mathbf{5 h}(0.661 \mathrm{~g}, 76.2 \%)$ as a white solid. M.p. 104.0-105.0 ${ }^{\circ} \mathrm{C} .{ }^{1} \mathrm{H}$ NMR (400 $\left.\mathrm{MHz}, \mathrm{CD}_{3} \mathrm{OD}\right): \delta=3.72\left(\mathrm{~s}, 3 \mathrm{H}, \mathrm{COOCH}_{3}\right), 4.90-4.93$ $(\mathrm{m}, 1 \mathrm{H}, \alpha \mathrm{CH}), 5.26$ (br. d, $J=8.4 \mathrm{~Hz}, 1 \mathrm{H}, \mathrm{NH}), 5.41$ (d, $J=3.2 \mathrm{~Hz}, 1 \mathrm{H}, \beta \mathrm{CH}), 6.94(\mathrm{~s}, 2 \mathrm{H}, \mathrm{ArH}), 7.21-7.27(\mathrm{~m}$, 1H, ArH), 7.31-7.36 (m, 2H, ArH), 7.49-7.51 (m, 2H, ArH), 8.07 (br. s, 3H, OH) ppm. ${ }^{13} \mathrm{C}$ NMR (100.6 MHz, $\left.\mathrm{CD}_{3} \mathrm{OCD}_{3}\right): \delta=52.40\left(\mathrm{CO}_{2} \mathrm{CH}_{3}\right), 59.91(\alpha \mathrm{CH}), 73.78$ $(\beta C H), 107.56(2 \mathrm{CH}), 126.03(\mathrm{C}), 126.85(2 \mathrm{CH}), 128.19$ $(\mathrm{CH}), 128.85(2 \mathrm{CH}), 137.13(\mathrm{C}), 142.44(\mathrm{C}), 146.08$ (2C), $167.41(\mathrm{C}=\mathrm{O}), 171.65(\mathrm{C}=\mathrm{O}) \mathrm{ppm} . \mathrm{m} / \mathrm{z}$ (HRESIMS) 348.10785, $\left([\mathrm{M}+\mathrm{H}]^{+}, \quad \mathrm{C}_{17} \mathrm{H}_{18} \mathrm{NO}_{7}\right.$, requires 348.10833).

4.2.1.13. Synthesis of 4-hydroxybenzoyl-L-Ala-OMe, (10a) The general procedure described above was followed with 4-hydroxybenzoic acid $(0.345 \mathrm{~g}$, $2.500 \mathrm{mmol}$ ) and $\mathrm{HCl} . \mathrm{H}-\mathrm{L}-\mathrm{Ala}-\mathrm{OMe}$ to give compound 10a $(0.412 \mathrm{~g}, 73.9 \%)$ as a white solid (from ethyl acetate/petroleum ether). M.p. 168.0-169.0 ${ }^{\circ} \mathrm{C} .{ }^{1} \mathrm{H}$ NMR $\left(400 \mathrm{MHz}, \mathrm{CD}_{3} \mathrm{OCD}_{3}\right): \delta=1.48(\mathrm{~d}, J=7.2 \mathrm{~Hz}, 3 \mathrm{H}$, $\left.\beta \mathrm{CH}_{3}\right), 3.71$ (s, 3H, $\left.\mathrm{COOCH}_{3}\right), 4.62-4.69(\mathrm{~m}, 1 \mathrm{H}, \alpha \mathrm{CH})$, 6.91 (d, $J=8.8 \mathrm{~Hz}, 2 \mathrm{H}, \mathrm{ArH}), 7.76$ (br. d, $J=6.4 \mathrm{~Hz}$, $1 \mathrm{H}, \mathrm{NH}), 7.85(\mathrm{~d}, J=8.8 \mathrm{~Hz}, 2 \mathrm{H}, \mathrm{ArH}), 8.97(\mathrm{~s}, 1 \mathrm{H}$, $\mathrm{OH})$ ppm. ${ }^{13} \mathrm{C}$ NMR $\left(100.6 \mathrm{MHz}, \mathrm{CD}_{3} \mathrm{OCD}_{3}\right): \delta=17.67$ $\left(\mathrm{CCH}_{3}\right), 49.22(\alpha \mathrm{CH}), 52.18\left(\mathrm{CO}_{2} \mathrm{CH}_{3}\right), 115.70(2 \mathrm{CH})$, $126.40(\mathrm{C}), 130.13(2 \mathrm{CH}), 161.20(\mathrm{C}), 166.90(\mathrm{C}=\mathrm{O})$, $174.13(\mathrm{C}=\mathrm{O}) \mathrm{ppm} . \mathrm{m} / \mathrm{z}$ (HRESI-MS) 224.09190, $([\mathrm{M}+$ $\mathrm{H}]^{+}, \mathrm{C}_{11} \mathrm{H}_{14} \mathrm{NO}_{4}$, requires 224.09228).

4.2.1.14. Synthesis of 3,4-dihydroxybenzoyl-L-Ala-OMe, (10b) The general procedure described above was followed with protocatechuic acid $(0.385 \mathrm{~g}, 2.500 \mathrm{mmol})$ and $\mathrm{HCl} . \mathrm{H}-\mathrm{L}$-Ala-OMe to give compound $\mathbf{1 0 b}(0.207 \mathrm{~g}$, $34.6 \%)$ as a light yellow oil. ${ }^{1} \mathrm{H}$ NMR $(400 \mathrm{MHz}$,

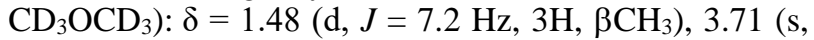
$\left.3 \mathrm{H}, \mathrm{COOCH}_{3}\right), 4.62-4.66(\mathrm{~m}, 1 \mathrm{H}, \alpha \mathrm{CH}), 6.88(\mathrm{~d}, J=8.0$ $\mathrm{Hz}, 1 \mathrm{H}, \mathrm{ArH}), 7.35-7.37$ (m, 1H, ArH), 7.47 (d, $J=2.0$ $\mathrm{Hz}, 1 \mathrm{H}, \mathrm{ArH}$ ), 7.67 (br. s, $1 \mathrm{H}, \mathrm{NH}$ ) ppm. ${ }^{13} \mathrm{C} \mathrm{NMR}$ $\left(100.6 \mathrm{MHz}, \mathrm{CD}_{3} \mathrm{OCD}_{3}\right): \delta=17.63\left(\mathrm{BCH}_{3}\right), 49.22$ $(\alpha \mathrm{CH}), 52.18\left(\mathrm{CO}_{2} \mathrm{CH}_{3}\right), 115.46(\mathrm{CH}), 115.67(\mathrm{CH})$, 120.47 (CH), 127.04 (C), 145.59 (C), 149.19 (C), 166.99 $(\mathrm{C}=\mathrm{O}), \quad 174.15 \quad(\mathrm{C}=\mathrm{O}) \quad \mathrm{ppm} . \quad \mathrm{m} / \mathrm{z} \quad$ (HRESI-MS) 240.08646, $\left([\mathrm{M}+\mathrm{H}]^{+}, \mathrm{C}_{11} \mathrm{H}_{14} \mathrm{NO}_{5}\right.$, requires 240.08720).

4.2.1.15. Synthesis of 2-(4-hydroxyphenyl)acetoyl-L-AlaOMe, $(\mathbf{1 0 c})$ The general procedure described above was followed with 2-(4-hydroxyphenyl)acetic acid $(0.380 \mathrm{~g}$, $2.500 \mathrm{mmol}$ ) and $\mathrm{HCl} . \mathrm{H}-\mathrm{L}-\mathrm{Ala}-\mathrm{OMe}$ to give compound 10c $(0.415 \mathrm{~g}, 69.9 \%)$ as a light pink solid (from ethyl acetate/petroleum ether). M.p. $97.0-98.0^{\circ} \mathrm{C} .{ }^{1} \mathrm{H}$ NMR $\left(400 \mathrm{MHz}, \mathrm{CDCl}_{3}\right): \delta=1.36\left(\mathrm{~d}, J=7.2 \mathrm{~Hz}, 3 \mathrm{H}, \beta \mathrm{CH}_{3}\right)$, $3.53\left(\mathrm{~s}, 2 \mathrm{H}, \mathrm{ARCH}_{2}\right), 3.73\left(\mathrm{~s}, 3 \mathrm{H}, \mathrm{COOCH}_{3}\right), 4.57-4.61$ $(\mathrm{m}, 1 \mathrm{H}, \alpha \mathrm{CH}), 6.01$ (br. s, $1 \mathrm{H}, \mathrm{NH}), 6.81(\mathrm{~d}, J=7.6 \mathrm{~Hz}$, $2 \mathrm{H}, \mathrm{ArH}), 7.13(\mathrm{~d}, J=7.6 \mathrm{~Hz}, 2 \mathrm{H}, \mathrm{ArH}) \mathrm{ppm} .{ }^{13} \mathrm{C} \mathrm{NMR}$ $\left(100.6 \mathrm{MHz}, \mathrm{CDCl}_{3}\right): \delta=17.84\left(\beta_{3} \mathrm{CH}_{3}\right), 42.46\left(\mathrm{CH}_{2}\right)$, $48.75(\alpha \mathrm{CH}), 52.18\left(\mathrm{CO}_{2} \mathrm{CH}_{3}\right), 115.92(2 \mathrm{CH}), 127.52$ (C), $130.99(2 \mathrm{CH}), 157.02(\mathrm{C}), 171.33(\mathrm{C}=\mathrm{O}), 173.88$ $(\mathrm{C}=\mathrm{O}) \mathrm{ppm} . \mathrm{m} / \mathrm{z}$ (HRESI-MS) 238.10728, $\left([\mathrm{M}+\mathrm{H}]^{+}\right.$, $\mathrm{C}_{12} \mathrm{H}_{16} \mathrm{NO}_{4}$, requires 238.10793).

4.2.1.16. Synthesis of 2-(3,4-dihydroxyphenyl)acetoyl-LAla-OMe, (10d) The general procedure described above was followed with 2-(3,4-dihydroxyphenyl)acetic acid $(0.420 \mathrm{~g}, 2.500 \mathrm{mmol})$ and $\mathrm{HCl} . \mathrm{H}-\mathrm{L}-\mathrm{Ala}-\mathrm{OMe}$ to give compound 10d $(0.327 \mathrm{~g}, 51.7 \%)$ as a light pink oil. ${ }^{1} \mathrm{H}$ NMR $\left(400 \mathrm{MHz}, \mathrm{CD}_{3} \mathrm{OCD}_{3}\right): \delta=1.34(\mathrm{~d}, J=7.2 \mathrm{~Hz}$, $\left.3 \mathrm{H}, \quad \mathrm{CCH}_{3}\right), 3.40\left(\mathrm{~s}, 2 \mathrm{H}, \mathrm{ARCH}_{2}\right), 3.67 \quad(\mathrm{~s}, 3 \mathrm{H}$, $\left.\mathrm{COOCH}_{3}\right), 4.43-4.46(\mathrm{~m}, 1 \mathrm{H}, \alpha \mathrm{CH}), 6.65(\mathrm{dd}, J=7.6$ $\mathrm{Hz}, J=2.0 \mathrm{~Hz} 1 \mathrm{H}, \mathrm{ArH}), 6.76(\mathrm{~d}, J=7.6 \mathrm{~Hz}, 1 \mathrm{H}, \mathrm{ArH})$, $6.84(\mathrm{~d}, J=2.0 \mathrm{~Hz}, 1 \mathrm{H}, \mathrm{ArH}), 7.37$ (br. s, $1 \mathrm{H}, \mathrm{NH}), 7.90$ (br. s, 2H, 2OH) ppm. ${ }^{13} \mathrm{C}$ NMR (100.6 MHz, $\left.\mathrm{CD}_{3} \mathrm{OCD}_{3}\right): \delta=17.82\left(\beta_{\mathrm{CH}}\right), 42.75 \quad\left(\mathrm{CH}_{2}\right), 48.78$ $(\alpha \mathrm{CH}), 52.20\left(\mathrm{CO}_{2} \mathrm{CH}_{3}\right), 115.89(\mathrm{CH}), 117.10(\mathrm{CH})$, $121.36(\mathrm{CH}), 128.19(\mathrm{C}), 144.72(\mathrm{C}), 145.76(\mathrm{C}), 171.45$ $(\mathrm{C}=\mathrm{O}), \quad 173.87 \quad(\mathrm{C}=\mathrm{O}) \quad \mathrm{ppm} . \quad \mathrm{m} / \mathrm{z} \quad$ (HRESI-MS) 254.10208, $\left([\mathrm{M}+\mathrm{H}]^{+}, \mathrm{C}_{12} \mathrm{H}_{16} \mathrm{NO}_{5}\right.$, requires 254.10285).

4.2.1.17. Synthesis of p-coumaroyl-L-Ala-OMe, (10e) The general procedure described above was followed with $p$-coumaric acid $(0.410 \mathrm{~g}, 2.500 \mathrm{mmol})$ and $\mathrm{HCl} . \mathrm{H}$ $L$-Ala-OMe to give compound 10e $(0.485 \mathrm{~g}, 77.8 \%)$ as a white solid (from methanol/diethyl ether). M.p. 123.0$125.0^{\circ} \mathrm{C} .{ }^{1} \mathrm{H}$ NMR $\left(400 \mathrm{MHz}, \mathrm{CD}_{3} \mathrm{OCD}_{3}\right): \delta=1.42(\mathrm{~d}, J$ $\left.=7.2 \mathrm{~Hz}, 3 \mathrm{H}, \mathrm{\beta CH}_{3}\right), 3.71\left(\mathrm{~s}, 3 \mathrm{H}, \mathrm{COOCH}_{3}\right), 4.56-4.64$ $(\mathrm{m}, 1 \mathrm{H}, \alpha \mathrm{CH}), 6.59(\mathrm{~d}, J=15.6 \mathrm{~Hz}, 1 \mathrm{H}, \mathrm{Ar}-\mathrm{CH}=\mathrm{CH}-$ ), 6.89 (d, $J=8.8 \mathrm{~Hz}, 2 \mathrm{H}, \mathrm{ArH}), 7.46-7.53(\mathrm{~m}, 4 \mathrm{H}, \mathrm{ArH}+$ $\mathrm{NH}+\mathrm{Ar}-\mathrm{CH}=\mathrm{CH}-$ ), 8.89 (br. s, $1 \mathrm{H}, \mathrm{OH})$ ppm. ${ }^{13} \mathrm{C} \mathrm{NMR}$ $\left(100.6 \mathrm{MHz}, \quad \mathrm{CD}_{3} \mathrm{OCD}_{3}\right): \delta=17.99\left(\beta_{\mathrm{CH}}\right), 48.80$ $(\alpha \mathrm{CH}), 52.22\left(\mathrm{CO}_{2} \mathrm{CH}_{3}\right), 116.56(2 \mathrm{CH}), 118.88(\mathrm{CH})$, $127.60(\mathrm{C}), 130.21(2 \mathrm{CH}), 140.91(\mathrm{CH}), 159.85(\mathrm{C})$, $166.18(\mathrm{C}=\mathrm{O}), 174.01(\mathrm{C}=\mathrm{O}) \mathrm{ppm} . \mathrm{m} / \mathrm{z}$ (HRESI-MS) 250.10705, $\left([\mathrm{M}+\mathrm{H}]^{+}, \mathrm{C}_{13} \mathrm{H}_{16} \mathrm{NO}_{4}\right.$, requires 250.10793).

4.2.1.18. Synthesis of caffeoyl-L-Ala-OMe, (10f) The general procedure described above was followed with caffeic acid $(0.450 \mathrm{~g}, 2.500 \mathrm{mmol})$ and $\mathrm{HCl} . \mathrm{H}-\mathrm{L}$-AlaOMe to give compound $\mathbf{1 0 f}(0.486 \mathrm{~g}, 73.3 \%)$ as a white solid. (from ethyl acetate/petroleum ether). M.p. 151.0$152.0{ }^{\circ} \mathrm{C} .{ }^{1} \mathrm{H}$ NMR $\left(400 \mathrm{MHz}, \mathrm{CD}_{3} \mathrm{COCD}_{3}\right): \delta=1.42(\mathrm{~d}$, $\left.J=7.2 \mathrm{~Hz}, 3 \mathrm{H}, \beta_{\mathrm{CH}}\right), 3.71\left(\mathrm{~s}, 3 \mathrm{H}, \mathrm{COOCH}_{3}\right), 4.56-4.63$ $(\mathrm{m}, 1 \mathrm{H}, \alpha \mathrm{CH}), 6.54(\mathrm{~d}, J=15.6 \mathrm{~Hz}, 1 \mathrm{H}, \mathrm{Ar}-\mathrm{CH}=\mathrm{CH}-$ ), $6.87(\mathrm{~d}, J=8.0 \mathrm{~Hz}, 1 \mathrm{H}, \operatorname{ArH}), 6.96-6.99(\mathrm{~m}, 1 \mathrm{H}, \operatorname{ArH})$, $7.11(\mathrm{~d}, J=2.0 \mathrm{~Hz}, 1 \mathrm{H}, \mathrm{ArH}), 7.45(\mathrm{~d}, J=15.6 \mathrm{~Hz}, 1 \mathrm{H}$, Ar- $\mathrm{CH}=\mathrm{CH}-$ ), 7.52 (br. d, $J=7.2 \mathrm{~Hz}, 1 \mathrm{H}, \mathrm{NH}$ ), 8.15 (s, $1 \mathrm{H}, \mathrm{OH}), 8.38$ (s, $1 \mathrm{H}, \mathrm{OH}) \mathrm{ppm} .{ }^{13} \mathrm{C} \mathrm{NMR}(100.6 \mathrm{MHz}$, $\left.\mathrm{CD}_{3} \mathrm{OCD}_{3}\right): \delta=17.95\left(\beta \mathrm{CH}_{3}\right), 48.80(\alpha \mathrm{CH}), \quad 52.22$ $\left(\mathrm{CO}_{2} \mathrm{CH}_{3}\right), 114.84(\mathrm{CH}), 116.29(\mathrm{CH}), 118.95(\mathrm{CH})$, $121.67(\mathrm{CH}), 128.30(\mathrm{C}), 141.27(\mathrm{CH}), 146.22(\mathrm{C})$, $147.92(\mathrm{C}), 166.19(\mathrm{C}=\mathrm{O}), 174.01(\mathrm{C}=\mathrm{O}) \mathrm{ppm} . \mathrm{m} / \mathrm{z}$ (HRESI-MS) 266.10191, $\left([\mathrm{M}+\mathrm{H}]^{+}, \quad \mathrm{C}_{13} \mathrm{H}_{16} \mathrm{NO}_{5}\right.$, requires 266.10285 ).

4.2.1.19. Synthesis of hydrocaffeoyl-L-Ala-OMe, (10g) The general procedure described above was followed with hydrocaffeic acid $(0.455 \mathrm{~g}, 2.500 \mathrm{mmol})$ and $\mathrm{HCl} . \mathrm{H}-\mathrm{L}$-Ala-OMe to give compound $\mathbf{1 0 g}(0.414 \mathrm{~g}$, $62.0 \%)$ as a colourless oil. ${ }^{1} \mathrm{H}$ NMR $(400 \mathrm{MHz}$, $\left.\mathrm{CD}_{3} \mathrm{OCD}_{3}\right): \delta=1.33\left(\mathrm{~d}, J=7.2 \mathrm{~Hz}, 3 \mathrm{H}, \beta \mathrm{CH}_{3}\right), 2.45-$ $2.49\left(\mathrm{~m}, 2 \mathrm{H}, \mathrm{CH}_{2}\right), 2.77-2.81\left(\mathrm{~m}, 2 \mathrm{H}, \mathrm{CH}_{2}\right), 3.68(\mathrm{~s}, 3 \mathrm{H}$, $\left.\mathrm{OCH}_{3}\right), 4.44-4.51(\mathrm{~m}, 1 \mathrm{H}, \alpha \mathrm{CH}), 6.57(\mathrm{dd}, J=2.0 \mathrm{~Hz}, J$ $=8.0 \mathrm{~Hz}, 1 \mathrm{H}, \mathrm{ArH}), 6.73-6.75(\mathrm{~m}, 2 \mathrm{H}, \mathrm{ArH}), 7.44$ (br. d, $J=6.8 \mathrm{~Hz}, 1 \mathrm{H}, \mathrm{NH}), 7.75$ (br. s, $2 \mathrm{H}, 2 \mathrm{OH}$ ) ppm. ${ }^{13} \mathrm{C}$ NMR (100.6 MHz, $\left.\mathrm{CD}_{3} \mathrm{OCD}_{3}\right): \delta=17.78\left(\beta_{C_{3}}\right), 31.60$ $\left(\mathrm{CH}_{2}\right), 38.52\left(\mathrm{CH}_{2}\right), 48.66(\alpha \mathrm{CH}), 52.21\left(\mathrm{CO}_{2} \mathrm{CH}_{3}\right)$, $115.93(\mathrm{CH}), 116.22(\mathrm{CH}), 120.30(\mathrm{CH}), 133.84(\mathrm{C})$, $144.02(\mathrm{C}), 145.68(\mathrm{C}), 172.71(\mathrm{C}=\mathrm{O}), 173.88(\mathrm{C}=\mathrm{O})$ 
ppm. $\mathrm{m} / \mathrm{z}$ (HRESI-MS) 268.11757, $\quad\left([\mathrm{M}+\mathrm{H}]^{+}\right.$, $\mathrm{C}_{13} \mathrm{H}_{18} \mathrm{NO}_{5}$, requires 268.11850).

4.2.2. Synthesis of the methyl ester of $N$-(4hydroxybenzoyl) dehydroalanine

Synthesis of 4-hydroxybenzoyl-_Ala-OMe (4a) To a solution of $\mathbf{1 a}(0.239 \mathrm{~g}, 1.000 \mathrm{mmol})$ in dry acetonitrile $\left(0.200 \mathrm{mmol} \quad \mathrm{dm}^{-3}\right), \quad 0.1 \quad$ equiv. of dimethylaminopyridine was added, followed by 2.5 equiv. of tert-butyldicarbonate. The reaction was monitored by TLC (ethyl acetate) until all the reactant had been fully tert-butyloxycarbonylated. The solvent was evaporated at reduced pressure and the residue was dissolved in ethyl acetate $\left(60 \mathrm{~cm}^{3}\right)$ and washed with $\mathrm{KHSO}_{4}\left(1 \mathrm{~mol} \mathrm{dm}^{-3}\right), \mathrm{NaHCO}_{3}\left(1 \mathrm{~mol} \mathrm{dm}^{-3}\right)$ and brine (3 times $15 \mathrm{~cm}^{3}$ each). The organic layer was dried with $\mathrm{MgSO}_{4}$ and the solvent evaporated at reduced pressure. Removal of the solvent afforded 2a $(0.300 \mathrm{~g}$, 68.4\%). ${ }^{1} \mathrm{H}$ NMR (400 MHz, $\left.\mathrm{CDCl}_{3}\right): \delta=1.47(\mathrm{~s}, 9 \mathrm{H}$, $\mathrm{CH}_{3}$ Boc), 1.57 (s, 9H, $\left.\mathrm{CH}_{3} \mathrm{Boc}\right), 3.82$ (s, 3H, $\left.\mathrm{COOCH}_{3}\right), 4.46\left(\mathrm{dd}, J=3.6 \mathrm{~Hz}, J=11.2 \mathrm{~Hz}, 1 \mathrm{H}, \beta \mathrm{CH}_{2}\right)$, $4.61\left(\mathrm{dd}, J=3.6 \mathrm{~Hz}, J=11.2 \mathrm{~Hz}, 1 \mathrm{H}, \beta \mathrm{CH}_{2}\right), 5.01-5.04$ $(\mathrm{m}, 1 \mathrm{H}, \alpha \mathrm{CH}), 7.00(\mathrm{~d}, J=7.6 \mathrm{~Hz}, 1 \mathrm{H}, \mathrm{NH}), 7.28(\mathrm{~d}, J=$ $8.8 \mathrm{~Hz}, 2 \mathrm{H}, \mathrm{ArH}), 7.86(\mathrm{~d}, J=8.8 \mathrm{~Hz}, 2 \mathrm{H}, \operatorname{ArH})$ ppm. ${ }^{13} \mathrm{C}$ NMR $\left(100.6 \mathrm{MHz}, \mathrm{CDCl}_{3}\right): \delta=27.64$ $\left[2 \mathrm{C}\left(\mathrm{CH}_{3}\right)_{3}\right], \quad 52.48(\alpha \mathrm{CH}), \quad 52.95 \quad\left(\mathrm{CO}_{2} \mathrm{CH}_{3}\right), \quad 66.05$ $\left(\mathrm{BCH}_{2}\right), 83.08\left[\mathrm{OC}\left(\mathrm{CH}_{3}\right)_{3}\right], 84.07\left[\mathrm{OC}\left(\mathrm{CH}_{3}\right)_{3}\right], 121.36$ $(2 \mathrm{CH}), 128.66(2 \mathrm{CH}), 130.86(\mathrm{C}), 151.11(\mathrm{C}=\mathrm{O}), 153.23$ $(\mathrm{C}=\mathrm{O}), 153.82(\mathrm{C}), 166.18(\mathrm{C}=\mathrm{O}), 169.75(\mathrm{C}=\mathrm{O}) \mathrm{ppm}$. $\mathrm{m} / \mathrm{z}$ (HRESI-MS) 440.19085, $\left([\mathrm{M}+\mathrm{H}]^{+}, \mathrm{C}_{21} \mathrm{H}_{30} \mathrm{NO}_{9}\right.$, requires 440.19206). Compound 2a $(0.300 \mathrm{~g}, 0.684$ mmol) was redissolved in acetonitrile $\left(0.200 \mathrm{~mol} \mathrm{dm}^{-3}\right)$ and $4 \%$ in volume of $N, N, N^{\prime}, N^{\prime}$-tetramethylguanidine was added, stirring was continued and the reaction followed by TLC. When the bis-tert-butyloxycarbonate derivative was consumed, the solvent was evaporated at reduced pressure. The residue was dissolved in ethyl acetate $\left(60 \mathrm{~cm}^{3}\right)$ and washed with $\mathrm{KHSO}_{4}\left(1 \mathrm{~mol} \mathrm{dm}^{-3}\right)$, and brine ( 3 times $15 \mathrm{~cm}^{3}$ each). The organic layer was dried with $\mathrm{MgSO}_{4}$ and the solvent evaporated at reduced pressure. Removal of the solvent afforded 3a $(0.068 \mathrm{~g}$, $31.0 \%){ }^{1} \mathrm{H}$ NMR $\left(400 \mathrm{MHz}, \mathrm{CDCl}_{3}\right): \delta=1.58(\mathrm{~s}, 9 \mathrm{H}$, $\left.\mathrm{CH}_{3} \mathrm{Boc}\right), 3.91\left(\mathrm{~s}, 3 \mathrm{H}, \mathrm{COOCH}_{3}\right), 6.01\left(\mathrm{~s}, 1 \mathrm{H}, \mathrm{CCH}_{2}\right)$, $6.79\left(\mathrm{~s}, 1 \mathrm{H}, \beta \mathrm{CH}_{2}\right), 7.30(\mathrm{~d}, J=8.8 \mathrm{~Hz}, 2 \mathrm{H}, \mathrm{ArH}), 7.87$ (d, $J=8.8 \mathrm{~Hz}, 2 \mathrm{H}, \mathrm{ArH}), 8.49$ (br. s, $1 \mathrm{H}, \mathrm{NH}) \mathrm{ppm} .{ }^{13} \mathrm{C}$ NMR $\left(100.6 \mathrm{MHz}, \mathrm{CDCl}_{3}\right): \delta=27.66\left[\mathrm{C}\left(\mathrm{CH}_{3}\right)_{3}\right], 53.13$ $\left(\mathrm{CO}_{2} \mathrm{CH}_{3}\right), 84.19\left[\mathrm{OC}\left(\mathrm{CH}_{3}\right)_{3}\right], 109.03\left(\beta_{\mathrm{CH}}\right), 121.61$ $(2 \mathrm{CH}), 128.44(2 \mathrm{CH}), 130.96(\mathrm{C}), 131.66(\mathrm{C}), 151.14$ $(\mathrm{C}=\mathrm{O}), 153.90(\mathrm{C}), 164.75(\mathrm{C}=\mathrm{O}), 164.87(\mathrm{C}=\mathrm{O}) \mathrm{ppm}$. $\mathrm{m} / \mathrm{z}$ (HRESI-MS) 322.12785, ([M + H $]^{+}, \mathrm{C}_{16} \mathrm{H}_{20} \mathrm{NO}_{6}$, requires 322.12906). Compound 3a $(0.068 \mathrm{~g}, 0.212$ mmol) was dissolved in dichloromethane $\left(0.1 \mathrm{~mol} \mathrm{dm}^{-3}\right)$ and $25 \%$ of TFA was slowly added with vigorous stirring. The reaction was monitored by TLC and when no starting material was detected $(\approx 1$ hour) an additional $50 \mathrm{~mL}$ of dichloromethane were added. The organic phase was washed with $\mathrm{NaHCO}_{3}\left(1 \mathrm{~mol} \mathrm{dm}^{-3}\right)$ and brine (3 times $15 \mathrm{~cm}^{3}$ each). The organic layer was dried with $\mathrm{MgSO}_{4}$ and the solvent evaporated at reduced pressure to give compound $4 \mathbf{a}(0.022 \mathrm{~g}, 47.1 \%)$ as a white solid. M.p. 205.0-206.0 ${ }^{\circ} \mathrm{C} .{ }^{1} \mathrm{H}$ NMR (400 MHz, $\left.\mathrm{CD}_{3} \mathrm{OCD}_{3}\right): \delta$ $=3.89\left(\mathrm{~s}, 3 \mathrm{H}, \mathrm{COOCH}_{3}\right), 5.84\left(\mathrm{~d}, J=1.2 \mathrm{~Hz}, 1 \mathrm{H}, \beta_{\mathrm{CH}}\right)$, $6.57\left(\mathrm{~d}, J=1.6,1 \mathrm{H}, \beta \mathrm{CH}_{2}\right), 6.99(\mathrm{~d}, J=8.8 \mathrm{~Hz}, 2 \mathrm{H}$, ArH), 7.84 (d, $J=8.8 \mathrm{~Hz}, 2 \mathrm{H}, \mathrm{ArH}), 8.71$ (br. s, 1H, NH) ppm. ${ }^{13} \mathrm{C}$ NMR (100.6 $\left.\mathrm{MHz}, \mathrm{CD}_{3} \mathrm{OCD}_{3}\right): \delta=53.20$ $\left(\mathrm{CO}_{2} \mathrm{CH}_{3}\right), 107.96,108.06\left(\mathrm{CCH}_{2}\right), 116.15(2 \mathrm{CH})$, 126.28 (C), 129.98 (2CH), 133.29 (C), 161.76 (C), 165.23, $165.27(\mathrm{C}=\mathrm{O}), 165.56,165.63(\mathrm{C}=\mathrm{O}) \mathrm{ppm} . \mathrm{m} / \mathrm{z}$ $($ HRESI-MS $)$ 222.07623, $\left([\mathrm{M}+\mathrm{H}]^{+}, \quad \mathrm{C}_{11} \mathrm{H}_{12} \mathrm{NO}_{4}\right.$, requires 222.07663 ).

4.2.3. Synthesis of the methyl esters of $N$-phenoyl and $N$ catechoyl dehydroalanine

General one-pot procedure for the synthesis of the methyl esters of $N$-phenoyl and $N$-catechoyl dehydroalanine

To a solution of the methyl ester of $N$-acyl serine in dry acetonitrile $\left(0.200 \quad\right.$ mol. $\left.\mathrm{dm}^{-3}\right), \quad 0.1$ equiv. of dimethylaminopyridine was added, followed by 2.5 equiv. of tert-butyldicarbonate for monohydroxylated phenol derivatives or 3.5 equiv. for catechol derivatives, under rapid stirring at room temperature. The reaction was monitored by TLC (ethyl acetate) until all the reactant had been fully tert-butyloxycarbonylated. Then, $4 \%$ in volume of $N, N, N^{\prime}, N^{\prime}$-tetramethylguanidine was added, stirring was continued and the reaction followed by TLC. When all the tert-butyloxycarbonylated derivative had beeen consumed, the solvent was evaporated at reduced pressure. The residue was redissolved in dichloromethane $\left(0.1 \mathrm{~mol} \mathrm{dm}^{-3}\right)$ and $25 \%$ of TFA was slowly added with vigorous stirring. The reaction was monitored by TLC and when no starting material was detected $(\approx 1$ hour $)$ an additional $50 \mathrm{~mL}$ of dichloromethane were added. The organic phase was washed with $\mathrm{KHSO}_{4}\left(1 \mathrm{~mol} \mathrm{dm}^{-3}\right), \mathrm{NaHCO}_{3}\left(1 \mathrm{~mol} \mathrm{dm}^{-3}\right)$ and brine (3 times $15 \mathrm{~cm}^{3}$ each). The organic layer was dried with $\mathrm{MgSO}_{4}$ and the solvent evaporated at reduced pressure.

4.2.3.1. Synthesis of 4-hydroxybenzoyl-_Ala-OMe, (4a) The general procedure described above was followed with $1 \mathrm{a}(0.239 \mathrm{~g}, 1.000 \mathrm{mmol})$ to give compound $\mathbf{4 a}$ $(0.104 \mathrm{~g}, 47.1 \%)$.

4.2.3.2. Synthesis of 2-(4-hydroxyphenyl)acetoyl-AAla$O M e,(4 c)$ The general procedure described above was followed with 1c $(0.253 \mathrm{~g}, 1.000 \mathrm{mmol})$ to give compound $4 \mathbf{c}(0.085 \mathrm{~g}, 36.2 \%)$ as a light yellow oil that solidified on standing. M.p. 102.0-103.0 ${ }^{\circ} \mathrm{C} .{ }^{1} \mathrm{H}$ NMR $\left(400 \mathrm{MHz}, \mathrm{CD}_{3} \mathrm{OCD}_{3}\right): \delta=3.66\left(\mathrm{~s}, 2 \mathrm{H}, \mathrm{CH}_{2}\right), 3.80(\mathrm{~s}$, $\left.3 \mathrm{H}, \mathrm{COOCH}_{3}\right), 5.74\left(\mathrm{~d}, J=1.2 \mathrm{~Hz}, 1 \mathrm{H}, \beta_{\mathrm{CH}_{2}}\right), 6.52(\mathrm{~s}$, $\left.1 \mathrm{H}, \beta \mathrm{CH}_{2}\right), 6.85(\mathrm{~d}, J=8.8 \mathrm{~Hz}, 2 \mathrm{H}, \operatorname{ArH}), 7.22(\mathrm{~d}, J=$ $8.8 \mathrm{~Hz}, 2 \mathrm{H}, \mathrm{ArH}$ ), 8.33 (br. s, $1 \mathrm{H}, \mathrm{NH}$ ) ppm. ${ }^{13} \mathrm{C}$ NMR $\left(100.6 \mathrm{MHz}, \quad \mathrm{CD}_{3} \mathrm{OCD}_{3}\right): \delta=43.76\left(\mathrm{CH}_{2}\right), \quad 53.06$ $\left(\mathrm{CO}_{2} \mathrm{CH}_{3}\right), 107.65\left(\mathrm{CCH}_{2}\right), 116.22(\mathrm{CH}), 116.27(\mathrm{CH})$, 126.79 (C), $131.26(2 \mathrm{CH}), 132.91$ (C), 157.38 (C), $164.80(\mathrm{C}=\mathrm{O}), 170.95(\mathrm{C}=\mathrm{O}) \mathrm{ppm} . \mathrm{m} / \mathrm{z}$ (HRESI-MS) 236.09161, $\left([\mathrm{M}+\mathrm{H}]^{+}, \mathrm{C}_{12} \mathrm{H}_{14} \mathrm{NO}_{4}\right.$, requires 236.09228).

4.2.3.3. Synthesis of p-coumaroyl- $\triangle A l a-O M e,(4 e)$ The general procedure described above was followed with $1 \mathrm{e}$ $(0.265 \mathrm{~g}, 1.000 \mathrm{mmol})$ to give compound $4 \mathrm{e}(0.169 \mathrm{~g}$, $68.4 \%$ ) as a white solid. M.p. 145.0-146.0 ${ }^{\circ} \mathrm{C} .{ }^{1} \mathrm{H}$ NMR $\left(400 \mathrm{MHz}, \mathrm{CD}_{3} \mathrm{OCD}_{3}\right): \delta=3.86\left(\mathrm{~s}, 3 \mathrm{H}, \mathrm{COOCH}_{3}\right), 5.82$ $\left(\mathrm{s}, 1 \mathrm{H}, \beta \mathrm{CH}_{2}\right), 6.68\left(\mathrm{~s}, 1 \mathrm{H}, \beta \mathrm{CH}_{2}\right), 6.89-6.93(\mathrm{~m}, 3 \mathrm{H}$, $\mathrm{ArH}+\mathrm{Ar}-\mathrm{CH}=\mathrm{CH}-), 7.54(\mathrm{~d}, J=8.4 \mathrm{~Hz}, 2 \mathrm{H}, \mathrm{ArH}), 7.59$ $(\mathrm{d}, J=15.6 \mathrm{~Hz}, 1 \mathrm{H}, \mathrm{Ar}-\mathrm{CH}=\mathrm{CH}-)$ ppm. ${ }^{13} \mathrm{C}$ NMR (100.6 $\left.\mathrm{MHz}, \mathrm{CD}_{3} \mathrm{OCD}_{3}\right): \delta=53.06\left(\mathrm{CO}_{2} \mathrm{CH}_{3}\right), 107.95\left(\beta_{\mathrm{CH}}\right)$, $116.58(2 \mathrm{CH}), 119.10(\mathrm{CH}), 127.50(\mathrm{C}), 130.58(2 \mathrm{CH})$, 
$133.40(\mathrm{C}), 142.33(\mathrm{CH}), 160.11(\mathrm{C}), 164.89(\mathrm{C}=\mathrm{O})$, $165.51(\mathrm{C}=\mathrm{O}) \mathrm{ppm} . \mathrm{m} / \mathrm{z}$ (HRESI-MS) 248.09138, $([\mathrm{M}+$ $\mathrm{H}]^{+}, \mathrm{C}_{13} \mathrm{H}_{14} \mathrm{NO}_{4}$, requires 248.09228).

4.2.3.4. Synthesis of caffeoyl-_Ala-OMe, (4f) The general procedure described above was followed with $\mathbf{1 f}$ $(0.281 \mathrm{~g}, 1.000 \mathrm{mmol})$ to give compound $\mathbf{4 f}(0.068 \mathrm{~g}$, $25.8 \%)$ as a light yellow solid. M.p. $174.0-175.0{ }^{\circ} \mathrm{C} .{ }^{1} \mathrm{H}$ NMR $\left(400 \mathrm{MHz}, \mathrm{CD}_{3} \mathrm{OCD}_{3}\right): \delta=3.86(\mathrm{~s}, 3 \mathrm{H}$, $\left.\mathrm{COOCH}_{3}\right), 5.81\left(\mathrm{~s}, 1 \mathrm{H}, \beta \mathrm{CH}_{2}\right), 6.67\left(\mathrm{~s}, 1 \mathrm{H}, \beta \mathrm{CH}_{2}\right), 6.85$ $(\mathrm{d}, J=15.6 \mathrm{~Hz}, 1 \mathrm{H}, \mathrm{Ar}-\mathrm{CH}=\mathrm{CH}-), 6.89(\mathrm{~d}, J=8.4 \mathrm{~Hz}$, $1 \mathrm{H}, \mathrm{ArH}), 7.04(\mathrm{dd}, J=2.0 \mathrm{~Hz}, J=8.4 \mathrm{~Hz}, 1 \mathrm{H}, \mathrm{ArH})$, $7.17(\mathrm{~d}, J=2.0 \mathrm{~Hz}, 1 \mathrm{H}, \mathrm{ArH}), 7.48(\mathrm{~d}, J=15.6 \mathrm{~Hz}, 1 \mathrm{H}$, $\mathrm{Ar}-\mathrm{CH}=\mathrm{CH}-) \quad$ ppm. ${ }^{13} \mathrm{C} \quad \mathrm{NMR} \quad(100.6 \mathrm{MHz}$, $\left.\mathrm{CD}_{3} \mathrm{OCD}_{3}\right): \delta=53.05\left(\mathrm{CO}_{2} \mathrm{CH}_{3}\right), 107.98\left(\beta_{\mathrm{CH}}\right), 115.06$ $(\mathrm{CH}), 116.24(\mathrm{CH}), 119.13(\mathrm{CH}), 122.08(\mathrm{CH}), 128.13$ (C), $133.32(\mathrm{C}), 142.72(\mathrm{CH}), 146.15$ (C), 148.15 (C), $164.89(\mathrm{C}=\mathrm{O}), 165.55(\mathrm{C}=\mathrm{O}) \mathrm{ppm} . \mathrm{m} / \mathrm{z}$ (HRESI-MS) 264.08645, $\left([\mathrm{M}+\mathrm{H}]^{+}, \mathrm{C}_{13} \mathrm{H}_{14} \mathrm{NO}_{5}\right.$, requires 264.08720).

4.2.4. Synthesis of the methyl ester of N-caffeoyl dehydrophenylalanine

Synthesis of caffeoyl-Z-APhe-OMe, (8f) To a solution of 5f $(0.357 \mathrm{~g}, 1.000 \mathrm{mmol})$ in dry acetonitrile $(0.200 \mathrm{~mol}$ $\mathrm{dm}^{-3}$ ), 0.1 equiv. of dimethylaminopyridine was added, followed by 3.5 equiv. of tert-butyldicarbonate. The reaction was monitored by TLC (ethyl acetate) until all the reactant had been fully tert-butyloxycarbonylated. The solvent was evaporated at reduced pressure and the residue was dissolved in ethyl acetate $\left(100 \mathrm{~cm}^{3}\right)$ and washed with $\mathrm{KHSO}_{4}\left(1 \mathrm{~mol} \mathrm{dm}^{-3}\right), \mathrm{NaHCO}_{3}\left(1 \mathrm{~mol} \mathrm{dm}^{-3}\right)$ and brine (3 times $25 \mathrm{~cm}^{3}$ each). The organic layer was dried with $\mathrm{MgSO}_{4}$ and the solvent evaporated at reduced pressure. Removal of the solvent afforded $6 \mathbf{f}(0.402 \mathrm{~g}$, 61.1\%). ${ }^{1} \mathrm{H}$ NMR (400 MHz, $\left.\mathrm{CDCl}_{3}\right): \delta=1.47(\mathrm{~s}, 9 \mathrm{H}$, $\mathrm{CH}_{3} \mathrm{Boc}$ ), 1.56 (s, 9H, $\mathrm{CH}_{3} \mathrm{Boc}$ ), 1.57 (s, 9H, $\mathrm{CH}_{3} \mathrm{Boc}$ ), $3.77\left(\mathrm{~s}, 3 \mathrm{H}, \mathrm{COOCH}_{3}\right), 5.19(\mathrm{dd}, J=3.2 \mathrm{~Hz}, J=9.4 \mathrm{~Hz}$, $1 \mathrm{H}, \alpha \mathrm{CH}), 6.18(\mathrm{~d}, J=3.2 \mathrm{~Hz}, 1 \mathrm{H}, \beta \mathrm{CH}), 6.35(\mathrm{~d}, J=$ $15.6 \mathrm{~Hz}, 1 \mathrm{H}, \mathrm{Ar}-\mathrm{CH}=\mathrm{CH}-), 7.28-7.40(\mathrm{~m}, 8 \mathrm{H}, \mathrm{ArH})$, $7.46(\mathrm{~d}, J=15.6 \mathrm{~Hz}, 1 \mathrm{H}, \mathrm{Ar}-\mathrm{CH}=\mathrm{CH}-) \mathrm{ppm} .{ }^{13} \mathrm{C} \mathrm{NMR}$ $\left(100.6 \mathrm{MHz}, \mathrm{CDCl}_{3}\right): \quad \delta=27.59 \quad\left[\mathrm{C}\left(\mathrm{CH}_{3}\right)_{3}\right], \quad 27.60$ $\left[\mathrm{C}\left(\mathrm{CH}_{3}\right)_{3}\right], 27.63\left[\mathrm{C}\left(\mathrm{CH}_{3}\right)_{3}\right], 52.79\left(\mathrm{CO}_{2} \mathrm{CH}_{3}\right), \quad 56.56$ $\begin{array}{lllll}(\alpha \mathrm{CH}), & 77.15 & (\beta \mathrm{CH}), \quad 83.32 & {\left[\mathrm{OC}\left(\mathrm{CH}_{3}\right)_{3}\right],} & 84.07\end{array}$ $\left[\mathrm{OC}\left(\mathrm{CH}_{3}\right)_{3}\right], 84.09\left[\mathrm{OC}\left(\mathrm{CH}_{3}\right)_{3}\right], 120.56(\mathrm{CH}), 121.97$ $(\mathrm{CH}), 123.41(\mathrm{CH}), 125.95(2 \mathrm{CH}), 126.13(\mathrm{CH}), 128.57$ $(2 \mathrm{CH}), 128.60(\mathrm{CH}), 133.21(\mathrm{C}), 135.90(\mathrm{C}), 140.39$ $(\mathrm{CH}), 142.76(\mathrm{C}), 143.53(\mathrm{C}), 150.39(\mathrm{C}=\mathrm{O}), 150.52$ $(\mathrm{C}=\mathrm{O}), \quad 152.26 \quad(\mathrm{C}=\mathrm{O}), \quad 165.08 \quad(\mathrm{C}=\mathrm{O}), \quad 169.80$ $(\mathrm{C}=\mathrm{O}) \mathrm{ppm} . \mathrm{m} / \mathrm{z}$ (HRESI-MS) 658.28506, $\left([\mathrm{M}+\mathrm{H}]^{+}\right.$, $\mathrm{C}_{34} \mathrm{H}_{44} \mathrm{NO}_{12}$, requires 658.28635). Compound 6f $(0.402$ $\mathrm{g}, 0.611 \mathrm{mmol})$ was redissolved in acetonitrile $(0.200$ mol $\mathrm{dm}^{-3}$ ) and $4 \%$ in volume of $N, N, N^{\prime}, N^{\prime}-$ tetramethylguanidine added, stirring was continued and the reaction followed by TLC. When all the tris-tertbutyloxycarbonate derivative was consumed, the solvent was evaporated at reduced pressure. The residue was dissolved in ethyl acetate $\left(100 \mathrm{~cm}^{3}\right)$ and washed with $\mathrm{KHSO}_{4}\left(1 \mathrm{~mol} \mathrm{dm} \mathrm{dm}^{-3}\right)$, and brine (3 times $25 \mathrm{~cm}^{3}$ each). The organic layer was dried with $\mathrm{MgSO}_{4}$ and the solvent evaporated at reduced pressure. Removal of the solvent afforded $7 f(0.255 \mathrm{~g}, 77.3 \%)$ as a light yellow solid. M.p. 149.0-150.0 ${ }^{1} \mathrm{H}$ NMR (400 MHz, $\left.\mathrm{CDCl}_{3}\right): \delta=1.56(\mathrm{~s}$, $9 \mathrm{H}, \mathrm{CH}_{3}$ Boc), 1.57 (s, 9H, $\mathrm{CH}_{3}$ Boc), 3.87 (s, 3H, $\left.\mathrm{COOCH}_{3}\right), 6.47$ (d, $J=15.6 \mathrm{~Hz}, 1 \mathrm{H}, \mathrm{Ar}-\mathrm{CH}=\mathrm{CH}-$ ), 7.29- $7.49(\mathrm{~m}, 8 \mathrm{H}, \mathrm{ArH}+\beta \mathrm{CH}), 7.62(\mathrm{~d}, J=15.6 \mathrm{~Hz}, 1 \mathrm{H}, \mathrm{Ar}-$ $\mathrm{CH}=\mathrm{CH}-)$ ppm. ${ }^{13} \mathrm{C}$ NMR (100.6 MHz, $\left.\mathrm{CDCl}_{3}\right): \delta=$ $27.60\left[2 \mathrm{C}\left(\mathrm{CH}_{3}\right)_{3}\right], 52.78\left(\mathrm{CO}_{2} \mathrm{CH}_{3}\right), 84.12\left[\mathrm{OC}\left(\mathrm{CH}_{3}\right)_{3}\right]$, $84.15\left[\mathrm{OC}\left(\mathrm{CH}_{3}\right)_{3}\right], 120.49(\mathrm{CH}), 122.01(\mathrm{CH}), 123.47$ $(\mathrm{CH}), 123.93(\mathrm{C}), 126.45(\mathrm{CH}), 128.63(\mathrm{CH}), 128.91$ $(\mathrm{CH}), 129.37(\mathrm{CH}), 129.54(\mathrm{CH}), 129.75(\mathrm{CH}), 131.98$ (CH), 133.15 (C), $133.77(\mathrm{C}), 141.43(\mathrm{CH}), 142.79(\mathrm{C})$, $143.71(\mathrm{C}), 150.39(\mathrm{C}=\mathrm{O}), 150.56(\mathrm{C}=\mathrm{O}), 163.73(\mathrm{C}=\mathrm{O})$, $165.71(\mathrm{C}=\mathrm{O}) \mathrm{ppm} . \mathrm{m} / \mathrm{z}$ (HRESI-MS) 540.22264, ([M + $\mathrm{H}]^{+}, \mathrm{C}_{29} \mathrm{H}_{34} \mathrm{NO}_{9}$, requires 540.22336). Compound $7 \mathbf{f}$ $(0.255 \mathrm{~g}, 0.473 \mathrm{mmol})$ was dissolved in dichloromethane $\left(0.1 \mathrm{~mol} \mathrm{dm}^{-3}\right)$ and $25 \%$ of TFA was slowly added with vigorous stirring. The reaction was monitored by TLC and when no starting material was detected $(\approx 1$ hour $)$ an additional $50 \mathrm{~mL}$ of dichloromethane were added. The organic phase was washed with $\mathrm{NaHCO}_{3}\left(1 \mathrm{~mol} \mathrm{dm}^{-3}\right)$ and brine (3 times $15 \mathrm{~cm}^{3}$ each). The organic layer was dried with $\mathrm{MgSO}_{4}$ and the solvent evaporated at reduced pressure to give compound $\mathbf{8 f}(0.097 \mathrm{~g}, 60.7 \%)$ as an orange oil. ${ }^{1} \mathrm{H}$ NMR $\left(400 \mathrm{MHz}, \mathrm{CD}_{3} \mathrm{OCD}_{3}\right): \delta=3.80(\mathrm{~s}$, $\left.3 \mathrm{H}, \mathrm{COOCH}_{3}\right), 6.74$ (d, $J=15.6 \mathrm{~Hz}, 1 \mathrm{H}, \mathrm{Ar}-\mathrm{CH}=\mathrm{CH}-$ ), $6.89(\mathrm{~d}, J=8.0 \mathrm{~Hz}, 1 \mathrm{H}, \mathrm{ArH}), 7.03(\mathrm{dd}, J=2.0 \mathrm{~Hz}, J=$ $8.0 \mathrm{~Hz}, 1 \mathrm{H}, \mathrm{ArH}), 7.16(\mathrm{~d}, J=2.0 \mathrm{~Hz}, 1 \mathrm{H}, \mathrm{ArH}), 7.27(\mathrm{~s}$, $1 \mathrm{H}, \beta \mathrm{CH}), 7.34-7.44(\mathrm{~m}, 3 \mathrm{H}, \mathrm{ArH}), 7.52(\mathrm{~d}, J=15.6 \mathrm{~Hz}$, $1 \mathrm{H}, \mathrm{Ar}-\mathrm{CH}=\mathrm{CH}-), 7.66(\mathrm{~d}, J=7.2 \mathrm{~Hz}, 2 \mathrm{H}, \mathrm{ArH}), 8.84$ (br. s, $1 \mathrm{H}, \quad \mathrm{NH}) \quad$ ppm. ${ }^{13} \mathrm{C}$ NMR $(100.6 \mathrm{MHz}$, $\left.\mathrm{CD}_{3} \mathrm{OCD}_{3}\right): \delta=52.47\left(\mathrm{CO}_{2} \mathrm{CH}_{3}\right), 114.94(\mathrm{CH}), 116.30$ $(\mathrm{CH}), 118.25(\mathrm{CH}), 122.00(\mathrm{CH}), 127.53(\mathrm{C}), 128.10$ (C), $129.38(2 \mathrm{CH}), 129.91(\mathrm{CH}), 130.64(2 \mathrm{CH}), 131.34$ $(\mathrm{CH}), 134,99(\mathrm{C}), 142.60(\mathrm{CH}), 146.19(\mathrm{C}), 148.17(\mathrm{C})$, $166.65(\mathrm{C}=\mathrm{O}), 166.49(\mathrm{C}=\mathrm{O}) \mathrm{ppm} . \mathrm{m} / \mathrm{z}$ (HRESI-MS) 340.11824, $\left([\mathrm{M}+\mathrm{H}]^{+}, \mathrm{C}_{19} \mathrm{H}_{18} \mathrm{NO}_{5}\right.$, requires 340.11850).

4.2.5. Synthesis of the methyl esters of $N$-phenoyl and $N$ catechoyl dehydrophenylalanine

General one-pot procedure for the synthesis of the methyl esters of N-phenoyl and N-catechoyl dehydrophenylalanine

To a solution of the methyl ester of $N$-acyl phenylserine in dry acetonitrile $\left(0.200 \mathrm{~mol} \mathrm{dm}^{-3}\right), \quad 0.1$ equiv. of dimethylaminopyridine was added, followed by 2.5 equiv. of tert-butyldicarbonate for monohydroxylated fenol derivatives or 3.5 equiv. for catechol derivatives, under rapid stirring at room temperature. The reaction was monitored by TLC (ethyl acetate) until all the reactant had been fully tert-butyloxycarbonylated. Then, $4 \%$ in volume of $N, N, N^{\prime}, N^{\prime}$-tetramethylguanidine was added, stirring was continued and the reaction followed by TLC. When all the tert-butyloxycarbonylated derivative had been consumed, the solvent was evaporated at reduced pressure. The residue was redissolved in dichloromethane $\left(0.1 \mathrm{~mol} \mathrm{dm}^{-3}\right)$ and $25 \%$ of TFA was slowly added with vigorous stirring. The reaction was monitored by TLC and when no starting material was detected $(\approx 1$ hour) an additional $50 \mathrm{~mL}$ of dichloromethane were added. The organic phase was washed with $\mathrm{KHSO}_{4}\left(1 \mathrm{~mol} \mathrm{dm}^{-3}\right), \mathrm{NaHCO}_{3}\left(1 \mathrm{~mol} \mathrm{dm}^{-3}\right)$ and brine (3 times $15 \mathrm{~cm}^{3}$ each). The organic layer was dried with $\mathrm{MgSO}_{4}$ and the solvent evaporated at reduced pressure.

4.2.5.1. Synthesis of 4-hydroxybenzoyl-Z-APhe-OMe, (8a) The general procedure described above was followed with $\mathbf{5 a}(0.315 \mathrm{~g}, 1.000 \mathrm{mmol})$ to give 
compound 8a $(0.168 \mathrm{~g}, 56.5 \%)$ as light green solid. M.p. 118.0-119.0 ${ }^{\circ} \mathrm{C} .{ }^{1} \mathrm{H}$ NMR (400 $\left.\mathrm{MHz}, \mathrm{CD}_{3} \mathrm{OCD}_{3}\right): \delta=$ $3.79\left(\mathrm{~s}, 3 \mathrm{H}, \mathrm{COOCH}_{3}\right), 6.97(\mathrm{~d}, J=8.4 \mathrm{~Hz}, 2 \mathrm{H}, \mathrm{ArH})$, 7.35-7.41 (m, 4H, ArH + $\beta \mathrm{CH}), 7.67-7.96(\mathrm{~m}, 2 \mathrm{H}, \mathrm{ArH})$, $7.96(\mathrm{~d}, J=8.4 \mathrm{~Hz}, 2 \mathrm{H}, \mathrm{ArH}), 9.04$ (br. s, 1H, NH) ppm. ${ }^{13} \mathrm{C}$ NMR $\left(100.6 \mathrm{MHz}, \mathrm{CD}_{3} \mathrm{OCD}_{3}\right): \delta=52.46$ $\left(\mathrm{CO}_{2} \mathrm{CH}_{3}\right), 115.97(2 \mathrm{CH}), 125.69(\mathrm{C}), 127.77$ (C), $129.36(2 \mathrm{CH}), 129.97(\mathrm{CH}), 130.58(2 \mathrm{CH}), 130.62$ $(2 \mathrm{CH}), 132.90(\mathrm{CH}), 134.80(\mathrm{C}), 135.00(\mathrm{C}), 161.96$ $(\mathrm{C}=\mathrm{O}), \quad 166.54 \quad(\mathrm{C}=\mathrm{O}) \quad \mathrm{ppm} . \quad \mathrm{m} / \mathrm{z} \quad$ (HRESI-MS) 298.10797, $\left([\mathrm{M}+\mathrm{H}]^{+}, \mathrm{C}_{17} \mathrm{H}_{16} \mathrm{NO}_{4}\right.$, requires 298.10793).

4.2.5.2. Synthesis of protocatechoyl-Z-APhe-OMe, (8b) The general procedure described above was followed with $\mathbf{5 b}(0.331 \mathrm{~g}, 1.000 \mathrm{mmol})$ to give compound $\mathbf{8 b}$ $(0.064 \mathrm{~g}, 20.5 \%)$ as a light orange oil. ${ }^{1} \mathrm{H}$ NMR (400 $\left.\mathrm{MHz}, \mathrm{CD}_{3} \mathrm{OCD}_{3}\right): \delta=3.79\left(\mathrm{~s}, 3 \mathrm{H}, \mathrm{COOCH}_{3}\right), 6.94(\mathrm{~d}, J$ $=8.4 \mathrm{~Hz}, 1 \mathrm{H}, \mathrm{ArH}), 7.36-7.42(\mathrm{~m}, 4 \mathrm{H}, \mathrm{ArH}+\beta \mathrm{CH})$, $7.50(\mathrm{dd}, J=2.0 \mathrm{~Hz}, J=8.4 \mathrm{~Hz}, 1 \mathrm{H}, \operatorname{ArH}), 7.57(\mathrm{~d}, J=$ $1.0 \mathrm{~Hz}, 2 \mathrm{H}, \mathrm{ArH}), 7.66-7.68(\mathrm{~m}, 2 \mathrm{H}, \mathrm{ArH}) \mathrm{ppm} .{ }^{13} \mathrm{C}$ NMR (100.6 MHz, $\left.\mathrm{CD}_{3} \mathrm{OCD}_{3}\right): \delta=52.45\left(\mathrm{CO}_{2} \mathrm{CH}_{3}\right)$, $115.63(\mathrm{CH}), 115.96(\mathrm{CH}), 121.01(\mathrm{CH}), 126.63(\mathrm{C})$, $127.81(\mathrm{C}), 129.37(2 \mathrm{CH}), 129.95(\mathrm{CH}), 130.64(2 \mathrm{CH})$, $132.75(\mathrm{CH}), 135.09(\mathrm{C}), 145.69(\mathrm{C}), 149.60(\mathrm{C}), 166.56$ $(2 \mathrm{C}=\mathrm{O}) \mathrm{ppm} . \mathrm{m} / \mathrm{z}$ (HRESI-MS) 314.10183, $\left([\mathrm{M}+\mathrm{H}]^{+}\right.$, $\mathrm{C}_{17} \mathrm{H}_{16} \mathrm{NO}_{5}$, requires 314.10285).

4.2.5.3. Synthesis of 2-(4-hydroxyphenyl)acetoyl-Z$\triangle P h e-O M e,(8 \mathrm{c})$ The general procedure described above was followed with $5 \mathrm{c}(0.329 \mathrm{~g}, 1.000 \mathrm{mmol})$ to give compound 8c $(0.196 \mathrm{~g}, 62.9 \%)$ as yellow solid. M.p. 54.0-55.0 ${ }^{\circ} \mathrm{C} .{ }^{1} \mathrm{H}$ NMR $\left(400 \mathrm{MHz}, \mathrm{CD}_{3} \mathrm{OCD}_{3}\right): \delta=3.63$ $\left(\mathrm{s}, 2 \mathrm{H}, \mathrm{CH}_{2}\right), 3.76\left(\mathrm{~s}, 3 \mathrm{H}, \mathrm{COOCH}_{3}\right), 6.86(\mathrm{~d}, \mathrm{~J}=8.4 \mathrm{~Hz}$, $2 \mathrm{H}, \mathrm{ArH}), 7.25-7.33(\mathrm{~m}, 6 \mathrm{H}, \mathrm{ArH}+\beta \mathrm{CH}), 7.46-7.50(\mathrm{~m}$, $2 \mathrm{H}, \mathrm{ArH}$ ), 8.64 (br. s, $1 \mathrm{H}, \mathrm{NH}) \mathrm{ppm} .{ }^{13} \mathrm{C} \mathrm{NMR}(100.6$ $\left.\mathrm{MHz}, \mathrm{CD}_{3} \mathrm{OCD}_{3}\right): \delta=42.88\left(\mathrm{CH}_{2}\right), 52.41\left(\mathrm{CO}_{2} \mathrm{CH}_{3}\right)$, $116.07(2 \mathrm{CH}), 126.77(\mathrm{C}), 127.23(\mathrm{C}), 129.23(2 \mathrm{CH})$, $129.91(\mathrm{CH}), 130.68(2 \mathrm{CH}), 131.20(2 \mathrm{CH}), 132.39(\mathrm{CH})$, $134.61(\mathrm{C}), 157.23(\mathrm{C}), 166.28(\mathrm{C}=\mathrm{O}), 171.00(\mathrm{C}=\mathrm{O})$ ppm. $\mathrm{m} / \mathrm{z}$ (HRESI-MS) 312.12415, $\quad\left([\mathrm{M}+\mathrm{H}]^{+}\right.$, $\mathrm{C}_{18} \mathrm{H}_{18} \mathrm{NO}_{4}$, requires 312.12358).

4.2.5.4. Synthesis of 2-(3,4-dihydroxyphenyl)acetoyl-Z$\triangle P h e-O M e,(8 d)$ The general procedure described above was followed with $\mathbf{5 d}(0.345 \mathrm{~g}, 1.000 \mathrm{mmol})$ to give compound 8d $(0.142 \mathrm{~g}, 43.3 \%)$ as a light yellow oil. ${ }^{1} \mathrm{H}$ NMR (400 MHz, $\left.\mathrm{CD}_{3} \mathrm{OCD}_{3}\right): \delta=3.57\left(\mathrm{~s}, 2 \mathrm{H}, \mathrm{CH}_{2}\right), 3.76$ $\left(\mathrm{s}, 3 \mathrm{H}, \mathrm{COOCH}_{3}\right), 6.76(\mathrm{dd}, J=1.6 \mathrm{~Hz}, J=8.0 \mathrm{~Hz}, 1 \mathrm{H}$, ArH), $6.84(\mathrm{~d}, J=8.0 \mathrm{~Hz}, 1 \mathrm{H}, \mathrm{ArH}), 6.94(\mathrm{~d}, J=1.6 \mathrm{~Hz}$, $1 \mathrm{H}, \operatorname{ArH}), 7.22(\mathrm{~s}, 1 \mathrm{H}, \beta \mathrm{CH}), 7.30-7.32(\mathrm{~m}, 3 \mathrm{H}, \mathrm{ArH})$, 7.47-7.49 (m, 2H, ArH), 7.91 (br. s, 1H, 2OH), 8.48 (s, $1 \mathrm{H}, \mathrm{NH}) \mathrm{ppm} .{ }^{13} \mathrm{C} \mathrm{NMR}\left(100.6 \mathrm{MHz}, \mathrm{CD}_{3} \mathrm{OCD}_{3}\right): \delta=$ $43.22\left(\mathrm{CH}_{2}\right), 52.40\left(\mathrm{CO}_{2} \mathrm{CH}_{3}\right), 116.02(\mathrm{CH}), 117.25$ $(\mathrm{CH}), 121.64(\mathrm{CH}), 127.26(\mathrm{C}), 127.62(\mathrm{C}), 129.29$ $(2 \mathrm{CH}), 129.90(\mathrm{CH}), 130.75(2 \mathrm{CH}), 132.05(\mathrm{CH}), 134.70$ (C), 144.88 (C), 145.89 (C), 166.34 (C=O), 170.61 $(\mathrm{C}=\mathrm{O}) \mathrm{ppm} . \mathrm{m} / \mathrm{z}$ (HRESI-MS) 328.11887, $\left([\mathrm{M}+\mathrm{H}]^{+}\right.$, $\mathrm{C}_{18} \mathrm{H}_{18} \mathrm{NO}_{5}$, requires 328.11850).

4.2.5.5. Synthesis of p-coumaroyl-Z-APhe-OMe, $(8 \boldsymbol{e})$ The general procedure described above was followed with $\mathbf{5 e}$ $(0.341 \mathrm{~g}, 1.000 \mathrm{mmol})$ to give compound 8e $(0.194 \mathrm{~g}$, $60.1 \%$ ) as a light yellow solid. (from ethyl acetate/petroleum ether). M.p. 187.0-188.0 ${ }^{\circ} \mathrm{C} .{ }^{1} \mathrm{H}$ NMR $\left(400 \mathrm{MHz}, \mathrm{CD}_{3} \mathrm{OCD}_{3}\right): \delta=3.80\left(\mathrm{~s}, 3 \mathrm{H}, \mathrm{COOCH}_{3}\right), 6.80$ $(\mathrm{d}, J=15.6 \mathrm{~Hz}, 1 \mathrm{H}, \mathrm{Ar}-\mathrm{CH}=\mathrm{CH}-), 6.92(\mathrm{~d}, J=8.4 \mathrm{~Hz}$,
2H, ArH), $7.28(\mathrm{~s}, 1 \mathrm{H}, \beta \mathrm{CH}), 7.35-7.44(\mathrm{~m}, 3 \mathrm{H}, \mathrm{ArH})$, $7.52(\mathrm{~d}, J=8.4 \mathrm{~Hz}, 2 \mathrm{H}, \mathrm{ArH}), 7.59(\mathrm{~d}, J=15.6 \mathrm{~Hz}, 1 \mathrm{H}$, Ar-CH=CH-), 7.67 (d, $J=7.2 \mathrm{~Hz}, 2 \mathrm{H}, \mathrm{ArH}), 8.88$ (br. s, $1 \mathrm{H}, \mathrm{NH}) \mathrm{ppm} .{ }^{13} \mathrm{C}$ NMR (100.6 MHz, $\left.\mathrm{CD}_{3} \mathrm{OCD}_{3}\right): \delta=$ $51.47\left(\mathrm{CO}_{2} \mathrm{CH}_{3}\right), 115.63(2 \mathrm{CH}), 117.17(\mathrm{CH}), 126.37$ (C), $126.67(\mathrm{C}), 128.38(2 \mathrm{CH}), 128.91(\mathrm{CH}), 129.49$ $(2 \mathrm{CH}), 129.65(2 \mathrm{CH}), 130.41(\mathrm{CH}), 133,99(\mathrm{C}), 141.27$ $(\mathrm{CH}), 159.20(\mathrm{C}), 164.69(\mathrm{C}=\mathrm{O}), 165.49(\mathrm{C}=\mathrm{O}) \mathrm{ppm}$. $\mathrm{m} / \mathrm{z}$ (HRESI-MS) 324.12348, $\left([\mathrm{M}+\mathrm{H}]^{+}, \mathrm{C}_{19} \mathrm{H}_{18} \mathrm{NO}_{4}\right.$, requires 324.12358 ).

4.2.5.6. Synthesis of caffeoyl-Z- $\triangle P$ Phe-OMe, (8f) The general procedure described above was followed with $\mathbf{5 f}$ $(0.357 \mathrm{~g}, 1.000 \mathrm{mmol})$ to give compound $\mathbf{8 f}(0.177 \mathrm{~g}$, $54.5 \%)$.

4.2.5.7. Synthesis of hydrocaffeoyl-Z-APhe-OMe, (8g) The general procedure described above was followed with $5 \mathrm{~g}(0.359 \mathrm{~g}, 1.000 \mathrm{mmol})$ to give compound $\mathbf{8 g}$ $(0.177 \mathrm{~g}, 52.0 \%)$ as a light yellow oil. ${ }^{1} \mathrm{H}$ NMR (400 $\left.\mathrm{MHz}, \mathrm{CD}_{3} \mathrm{OCD}_{3}\right): \delta=2.67\left(\mathrm{t}, J=7.2 \mathrm{~Hz}, 2 \mathrm{H}, \mathrm{CH}_{2}\right), 2.87$ $\left(\mathrm{t}, J=7.2 \mathrm{~Hz}, 2 \mathrm{H}, \mathrm{CH}_{2}\right), 3.77\left(\mathrm{~s}, 3 \mathrm{H}, \mathrm{OCH}_{3}\right), 6.63(\mathrm{dd}, J$ $=2.0 \mathrm{~Hz}, J=8.0 \mathrm{~Hz}, 1 \mathrm{H}, \mathrm{ArH}), 6.78(\mathrm{~d}, J=8.0 \mathrm{~Hz}, 1 \mathrm{H}$, $\operatorname{ArH}), 6.79(\mathrm{~d}, J=2.0 \mathrm{~Hz}, 1 \mathrm{H}, \mathrm{ArH}), 7.19(\mathrm{~s}, 1 \mathrm{H}, \beta \mathrm{CH})$, 7.33-7.39 (m, 3H, ArH), 7.49-7.51 (m, 2H, ArH), 7.77 (br. s, 2H, 2OH), 8.68 (s, 1H, NH) ppm. ${ }^{13} \mathrm{C} \mathrm{NMR} \mathrm{(100.6}$ $\left.\mathrm{MHz}, \mathrm{CD}_{3} \mathrm{OCD}_{3}\right): \delta=31.28\left(\mathrm{CH}_{2}\right), 38.54\left(\mathrm{CH}_{2}\right), 52.40$ $\left(\mathrm{CO}_{2} \mathrm{CH}_{3}\right), 115.99(\mathrm{CH}), 116.38(\mathrm{CH}), 120.48(\mathrm{CH})$, $127.67(\mathrm{C}), 129.37(2 \mathrm{CH}), 129.82(\mathrm{CH}), 130.62(2 \mathrm{CH})$, $131.53(\mathrm{CH}), 133.80(\mathrm{C}), 134.73(\mathrm{C}), 144.14(\mathrm{C}), 145.76$ (C), $166.42(\mathrm{C}=\mathrm{O}), 172.32(\mathrm{C}=\mathrm{O}) \mathrm{ppm} . \mathrm{m} / \mathrm{z}$ (HRESIMS) 342.13368, $\left([\mathrm{M}+\mathrm{H}]^{+}, \quad \mathrm{C}_{19} \mathrm{H}_{20} \mathrm{NO}_{5}\right.$, requires 342.13415).

4.2.5.8. Attempted synthesis of galloyl-Z-APhe-OMe, (8h) The general procedure described above was followed with $\mathbf{5 h}(0.347 \mathrm{~g}, 1.000 \mathrm{mmol})$ and 4.5 equiv. of tert-butyldicarbonate to give compound $\mathbf{H}-\mathbf{Z}-\Delta \mathbf{P h e}-$ OMe $(0.087 \mathrm{~g}, 48.8 \%)$ as a light yellow oil. ${ }^{1} \mathrm{H}$ NMR $\left(400 \mathrm{MHz}, \mathrm{CD}_{3} \mathrm{OCD}_{3}\right): \delta=3.77\left(\mathrm{~s}, 3 \mathrm{H}, \mathrm{COOCH}_{3}\right), 7.13$ $(\mathrm{s}, 1 \mathrm{H}, \beta \mathrm{CH}), 7.28-7.42(\mathrm{~m}, 3 \mathrm{H}, \mathrm{ArH}), 7.65-7.67(\mathrm{~m}, 2 \mathrm{H}$, ArH) ppm. $\left.{ }^{13} \mathrm{C} \mathrm{NMR} \mathrm{(100.6} \mathrm{MHz,} \mathrm{CD}_{3} \mathrm{OCD}_{3}\right): \delta=52.31$ $\left(\mathrm{CO}_{2} \mathrm{CH}_{3}\right), 129.24(2 \mathrm{CH}), 129.46(\mathrm{CH}), 129.95(\mathrm{CH})$, $130.53(2 \mathrm{CH}), 135.49$ (C), $156.97(\mathrm{C}), 167.23(\mathrm{C}=\mathrm{O})$ ppm. $\mathrm{m} / \mathrm{z}$ (HRESI-MS) 178.10899, $\left([\mathrm{M}+\mathrm{H}]^{+}\right.$, $\mathrm{C}_{10} \mathrm{H}_{12} \mathrm{NO}_{2}$, requires 178.08680).

4.2.6. Synthesis of C-deprotected $N$-phenoyl and $N$ catechoyl dehydrophenylalanines

4.2.6.1. Synthesis of protocatechoyl-Z- $\triangle P$ Pe- $O H$, (9b) To a solution of $\mathbf{5 b}(0.331 \mathrm{~g}, 1.000 \mathrm{mmol})$ in dry acetonitrile $\left(0.200 \mathrm{~mol} \mathrm{dm}^{-3}\right), 0.1$ equiv. of DMAP was added, followed by 3.5 equiv. of tert-butyldicarbonate. The reaction was monitored by TLC (ethyl acetate) until all the reactant had been fully tert-butyloxycarbonylated. Then $4 \%$ in volume of TMG was added, stirring was continued and the reaction followed by TLC. When all the tert-butyloxycarbonylated derivative was consumed, the solvent was evaporated at reduced pressure. The residue was dissolved in ethyl acetate $\left(100 \mathrm{~cm}^{3}\right)$ and washed with $\mathrm{KHSO}_{4}\left(1 \mathrm{~mol} \mathrm{dm}^{-3}\right)$, and brine (3 times 25 $\mathrm{cm}^{3}$ each). The organic layer was dried with $\mathrm{MgSO}_{4}$ and the solvent evaporated at reduced pressure. Removal of the solvent afforded $7 \mathbf{b}(0.372 \mathrm{~g}, 72.5 \%)$ as a yellow 
solid. ${ }^{1} \mathrm{H}$ NMR $\left(400 \mathrm{MHz}, \mathrm{CDCl}_{3}\right): \delta=1.49\left(\mathrm{~s}, 9 \mathrm{H}, \mathrm{CH}_{3}\right.$ Boc), 1.56 (s, 9H, $\mathrm{CH}_{3}$ Boc), $3.87\left(\mathrm{~s}, 3 \mathrm{H}, \mathrm{OCH}_{3}\right), 6.88$ $(\mathrm{d}, J=8.4 \mathrm{~Hz}, 1 \mathrm{H}, \operatorname{ArH}), 7.33-7.38(\mathrm{~m}, 3 \mathrm{H}, \operatorname{ArH}+$ $\beta \mathrm{CH}), 7.44-7.51(\mathrm{~m}, 5 \mathrm{H}, \mathrm{ArH}), 7.49(\mathrm{~s}, 1 \mathrm{H}, \mathrm{OH}), 7.96$ (s, $1 \mathrm{H}, \mathrm{OH}) \mathrm{ppm} .{ }^{13} \mathrm{C} \mathrm{NMR}\left(100.6 \mathrm{MHz}, \mathrm{CDCl}_{3}\right): \delta=27.55$

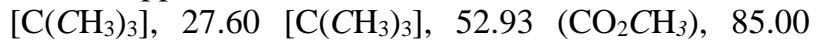
$\left[2 \mathrm{C}\left(\mathrm{CH}_{3}\right)_{3}\right], 117.82(\mathrm{CH}), 117.85(\mathrm{C}), 122.71(\mathrm{CH})$, $127.58(\mathrm{CH}), 128.70(\mathrm{CH}), 128.84(\mathrm{CH}), 129.69(\mathrm{CH})$, $130.85(\mathrm{CH}), 130.97(\mathrm{CH}), 132.31(\mathrm{CH}), 133.30(\mathrm{C})$, $133.57(\mathrm{C}), 138.94(\mathrm{C}), 150.96(\mathrm{C}=\mathrm{O}), 152.48(\mathrm{C}=\mathrm{O})$, $162.65(\mathrm{C}=\mathrm{O}), 167.74(\mathrm{C}=\mathrm{O}) \mathrm{ppm} . \mathrm{m} / \mathrm{z}$ (HRESI-MS) 514.18352, $\left([\mathrm{M}+\mathrm{H}]^{+}, \mathrm{C}_{27} \mathrm{H}_{32} \mathrm{NO}_{9}\right.$, requires 514.20771). Compound $7 \mathbf{b}(0.257 \mathrm{~g}, 0.500 \mathrm{mmol})$ was then dissolved in dioxane $\left(0.2 \mathrm{~mol} \mathrm{dm}^{-3}\right)$, followed by addition of $3 \mathrm{~cm}^{3}$ of $\mathrm{NaOH}\left(1 \mathrm{~mol} \mathrm{dm}^{-3}\right)$. The solution was stirred at room temperature for 2 hours and then $25 \%$ of TFA in volume was slowly added with vigorous stirring. The solution was stirred at room temperature for 2 hours after which the solvent was evaporated at reduced pressure. The residue was dissolved in water $\left(20 \mathrm{~cm}^{3}\right)$ and extracted with ethyl acetate $\left(5\right.$ times $\left.10 \mathrm{~cm}^{3}\right)$. The organic fractions were collected and washed with brine $\left(20 \mathrm{~cm}^{3}\right)$, dried with $\mathrm{MgSO}_{4}$ and the solvent evaporated at reduced pressure to give compound $\mathbf{9 b}(0.061 \mathrm{~g}, 40.8 \%)$ as a greenish oil. ${ }^{1} \mathrm{H}$ NMR (400 MHz, $\left.\mathrm{CD}_{3} \mathrm{OCD}_{3}\right): \delta=6.94$ $(\mathrm{d}, J=8.0 \mathrm{~Hz}, 1 \mathrm{H}, \mathrm{ArH}), 7.33-7.41(\mathrm{~m}, 3 \mathrm{H}, \mathrm{ArH}+$ $\beta \mathrm{CH}), 7.48-7.52(\mathrm{~m}, 2 \mathrm{H}, \mathrm{ArH}), 7.56-7.58(\mathrm{~m}, 1 \mathrm{H}, \mathrm{ArH})$, 7.69 (d, $J=7.2 \mathrm{~Hz}, 2 \mathrm{H}, \mathrm{ArH}) \mathrm{ppm} .{ }^{13} \mathrm{C} \mathrm{NMR}(100.6$ $\left.\mathrm{MHz}, \mathrm{CD}_{3} \mathrm{OCD}_{3}\right): \delta=115.59(\mathrm{CH}), 115.94(\mathrm{CH}), 120.99$ $(\mathrm{CH}), 126.73(\mathrm{C}), 127.65(\mathrm{C}), 129.30(2 \mathrm{CH}), 129.90$ $(\mathrm{CH}), 130.65(2 \mathrm{CH}), 133.27(\mathrm{CH}), 135.22(\mathrm{C}), 145.65$ (C), $149.55(\mathrm{C}), 166.54(\mathrm{C}=\mathrm{O}), 166.84(\mathrm{C}=\mathrm{O}) \mathrm{ppm} . \mathrm{m} / \mathrm{z}$ $($ HRESI-MS $)$ 300.08604, $\left([\mathrm{M}+\mathrm{H}]^{+}, \quad \mathrm{C}_{16} \mathrm{H}_{14} \mathrm{NO}_{5}\right.$, requires 300.08720$)$.

4.2.6.2. Synthesis of p-coumaroyl-Z- $\triangle P$ Pe- $O H,(9 e)$ The procedure described above for the synthesis of $\mathbf{7 b}$ was followed with $5 \mathbf{e}(0.341 \mathrm{~g}, 1.000 \mathrm{mmol})$ to give compound 7e $(0.221 \mathrm{~g}, 52.1 \%)$ as a light white solid. M.p. $153.0-154.0{ }^{\circ} \mathrm{C} .{ }^{1} \mathrm{H}$ NMR $\left(400 \mathrm{MHz}, \mathrm{CDCl}_{3}\right): \delta=$ 1.57 (s, 9H, $\left.\mathrm{CH}_{3} \mathrm{Boc}\right), 3.87$ (s, 3H, $\left.\mathrm{OCH}_{3}\right), 6.50$ (d, $J=$ $15.6 \mathrm{~Hz}, 1 \mathrm{H}, \mathrm{Ar}-\mathrm{CH}=\mathrm{CH}-), 7.20(\mathrm{~d}, J=8.4 \mathrm{~Hz}, 2 \mathrm{H}$, ArH), 7.33-7.39 (m, 3H, ArH), 7.44-7.53 (m, 5H, ArH + $\beta \mathrm{CH}), 7.66(\mathrm{~d}, J=15.6 \mathrm{~Hz}, 1 \mathrm{H}, \mathrm{Ar}-\mathrm{CH}=\mathrm{CH}-) \mathrm{ppm} .{ }^{13} \mathrm{C}$ NMR (100.6 MHz, $\left.\mathrm{CDCl}_{3}\right): \delta=27.58\left[\mathrm{C}\left(\mathrm{CH}_{3}\right)_{3}\right], 52.80$ $\left(\mathrm{CO}_{2} \mathrm{CH}_{3}\right), \quad 83.95\left[\mathrm{OC}\left(\mathrm{CH}_{3}\right)_{3}\right], 119.55(\mathrm{CH}), 121.70$ $(2 \mathrm{CH}), 123.98(\mathrm{C}), 128.62(\mathrm{CH}), 128.89(\mathrm{CH}), 129.13$ $(2 \mathrm{CH}), 129.39(\mathrm{CH}), 129.51(\mathrm{C}), 129.76(\mathrm{CH}), 130.36$ $(\mathrm{CH}), 131.88(\mathrm{CH}), 132.03(\mathrm{C}), 133.83(\mathrm{C}), 142.21$ $(\mathrm{CH}), 151.41(\mathrm{C}=\mathrm{O}), 152.31(\mathrm{C}=\mathrm{O}), 165.78(\mathrm{C}=\mathrm{O}) \mathrm{ppm}$. $\mathrm{m} / \mathrm{z}$ (HRESI-MS) 424.17479, $\left([\mathrm{M}+\mathrm{H}]^{+}, \mathrm{C}_{24} \mathrm{H}_{26} \mathrm{NO}_{6}\right.$, requires 424.17601). Compound 7e $(0.212 \mathrm{~g}, 0.500$ mmol) was reacted following the procedure described above for the synthesis of $9 \mathbf{b}$ to give $9 \mathrm{e}(0.086 \mathrm{~g}, 55.9 \%)$ as a light brown solid. M.p. 177.0-178.0 ${ }^{\circ} \mathrm{C} .{ }^{1} \mathrm{H}$ NMR $\left(400 \mathrm{MHz}, \mathrm{CD}_{3} \mathrm{OCD}_{3}\right): \delta=6.81(\mathrm{~d}, J=15.6 \mathrm{~Hz}, 1 \mathrm{H}, \mathrm{Ar}-$ $\mathrm{CH}=\mathrm{CH}-), 6.93(\mathrm{~d}, J=8.4 \mathrm{~Hz}, 2 \mathrm{H}, \mathrm{ArH}), 7.36-7.44(\mathrm{~m}$, $4 \mathrm{H}, \mathrm{ArH}+\beta \mathrm{CH}), 7.52(\mathrm{~d}, J=8.4 \mathrm{~Hz}, 2 \mathrm{H}, \mathrm{ArH}), 7.58(\mathrm{~d}$, $J=15.6 \mathrm{~Hz}, 1 \mathrm{H}, \mathrm{Ar}-\mathrm{CH}=\mathrm{CH}-), 7.67(\mathrm{~d}, J=7.2 \mathrm{~Hz}, 2 \mathrm{H}$, ArH), 8.78 (br. s, 1H, NH) ppm. ${ }^{13} \mathrm{C}$ NMR (100.6 MHz, $\left.\mathrm{CD}_{3} \mathrm{OCD}_{3}\right): \delta=116.58(2 \mathrm{CH}), 118.32(\mathrm{CH}), 127.34(\mathrm{C})$, $127.41(\mathrm{C}), 129.29(2 \mathrm{CH}), 129.82(\mathrm{CH}), 130.45(\mathrm{CH})$, $130.68(2 \mathrm{CH}), 131.44(\mathrm{CH}), 132.01(\mathrm{CH}), 135.23(\mathrm{C})$, $142.18(\mathrm{CH}), 160.20(\mathrm{C}=\mathrm{O}), 166.91(\mathrm{C}=\mathrm{O}) \mathrm{ppm} . \mathrm{m} / \mathrm{z}$
(HRESI-MS) 310.10703, $\left([\mathrm{M}+\mathrm{H}]^{+}, \quad \mathrm{C}_{18} \mathrm{H}_{16} \mathrm{NO}_{4}\right.$, requires 310.10793$)$.

4.2.6.3. Synthesis of caffeoyl-Z-APhe-OH, (9f) The procedure described above for the synthesis of $\mathbf{7 b}$ was followed with $\mathbf{5 f}(0.536 \mathrm{~g}, 1.500 \mathrm{mmol})$ to give $\mathbf{7 f}(0.382$ $\mathrm{g}, 47.2 \%)$. Compound $7 \mathbf{f}(0.270 \mathrm{~g}, 0.500 \mathrm{mmol})$ was reacted following the procedure described above for the synthesis of $\mathbf{9 b}$ to give 9 f $(0.103 \mathrm{~g}, 63.2 \%)$ as a light green oil. ${ }^{1} \mathrm{H} \mathrm{NMR}\left(400 \mathrm{MHz}, \mathrm{CD}_{3} \mathrm{OCD}_{3}\right): \delta=6.76(\mathrm{~d}, J$ $=15.6 \mathrm{~Hz}, 1 \mathrm{H}, \mathrm{Ar}-\mathrm{CH}=\mathrm{CH}-), 6.89(\mathrm{~d}, J=8.0 \mathrm{~Hz}, 1 \mathrm{H}$, ArH), 7.03 (d, $J=8.0 \mathrm{~Hz}, 1 \mathrm{H}, \mathrm{ArH}), 7.16$ (s, 1H, ArH), 7.34-7.43 (m, 4H, ArH), 7.53 (d, $J=15.6 \mathrm{~Hz}, 1 \mathrm{H}$, Ar$\mathrm{CH}=\mathrm{CH}-$ ), 7.67 (d, J=7.2 Hz, 2H, ArH), 8.80 (br. s, $1 \mathrm{H}$, $\mathrm{NH})$ ppm. ${ }^{13} \mathrm{C}$ NMR (100.6 $\left.\mathrm{MHz}, \mathrm{CD}_{3} \mathrm{OCD}_{3}\right): \delta=$ $114.94(\mathrm{CH}), 116.28(\mathrm{CH}), 118.38(\mathrm{CH}), 122.03(\mathrm{CH})$, $127.27(\mathrm{C}), 128.13(\mathrm{C}), 129.32(2 \mathrm{CH}), 129.90(\mathrm{CH})$, $130.70(2 \mathrm{CH}), 132.24(\mathrm{CH}), 135.14(\mathrm{C}), 142.65(\mathrm{CH})$, $146.11(\mathrm{C}), 148.10(\mathrm{C}), 165.83(\mathrm{C}=\mathrm{O}), 166.84(\mathrm{C}=\mathrm{O})$ ppm. $\mathrm{m} / \mathrm{z}$ (HRESI-MS) 326.10215, $\left([\mathrm{M}+\mathrm{H}]^{+}\right.$, $\mathrm{C}_{18} \mathrm{H}_{16} \mathrm{NO}_{5}$, requires 326.10285).

4.2.6.4. Synthesis of hydrocaffeoyl-Z- $\triangle P$ Phe-OH, $(9 \mathrm{~g})$ The procedure described above for the synthesis of $\mathbf{7 b}$ was followed with $\mathbf{5 g}(0.359 \mathrm{~g}, 1.000 \mathrm{mmol})$ to give compound $7 \mathrm{~g}(0.294 \mathrm{~g}, 54.3 \%)$ as a white solid. M.p. 156.0-157.0 ${ }^{\circ} \mathrm{C}$. ${ }^{1} \mathrm{H}$ NMR (400 MHz, $\left.\mathrm{CDCl}_{3}\right): \delta=1.55$ (s, $18 \mathrm{H}, \mathrm{CH}_{3}$ Boc), 2.63-2.65 (m, 2H, $\left.\mathrm{CH}_{2}\right), 2.99-3.00$ (m, 2H, $\left.\mathrm{CH}_{2}\right), 3.84$ (s, 3H, $\left.\mathrm{OCH}_{3}\right), 6.98$ (br. s, $\left.1 \mathrm{H}, \mathrm{ArH}\right)$, 7.08-7.18 (m, 3H, ArH + $\beta \mathrm{CH}), 7.33-7.37$ (m, 5H, ArH) ppm. ${ }^{13} \mathrm{C}$ NMR $\left(100.6 \mathrm{MHz}, \mathrm{CDCl}_{3}\right): \delta=27.62$ [2C $\left.\left(\mathrm{CH}_{3}\right)_{3}\right], 30.27\left(\mathrm{CH}_{2}\right), 30.90\left(\mathrm{CH}_{2}\right), 52.69\left(\mathrm{CO}_{2} \mathrm{CH}_{3}\right)$, $83.66\left[\mathrm{OC}\left(\mathrm{CH}_{3}\right)_{3}\right], 83.68\left[\mathrm{OC}\left(\mathrm{CH}_{3}\right)_{3}\right], 122.94(2 \mathrm{CH})$, $123.02(2 \mathrm{CH}), 124.14(\mathrm{C}), 126.32(\mathrm{CH}), 128.63(\mathrm{CH})$, $129.52(2 \mathrm{CH}), 132.14(\mathrm{CH}), 133.64(\mathrm{C}), 139.29(\mathrm{C})$, 140.89 (C), $142.35(\mathrm{C}), 150.77(\mathrm{C}=\mathrm{O}), 150.84(\mathrm{C}=\mathrm{O})$, $165.62(\mathrm{C}=\mathrm{O}), 170.29(\mathrm{C}=\mathrm{O}) \mathrm{ppm} . \mathrm{m} / \mathrm{z}$ (HRESI-MS) 542.23866, $\left([\mathrm{M}+\mathrm{H}]^{+}, \mathrm{C}_{29} \mathrm{H}_{36} \mathrm{NO}_{9}\right.$, requires 542.23901). Compound $7 \mathrm{~g}(0.288 \mathrm{~g}, 0.532 \mathrm{mmol})$ was reacted following the procedure described above for the synthesis of $9 \mathrm{~b}$ to give $9 \mathrm{~g}(0.086 \mathrm{~g}, 33.6 \%)$ as a light green oil. ${ }^{1} \mathrm{H}$ NMR (400 MHz, $\left.\mathrm{CD}_{3} \mathrm{OCD}_{3}\right): \delta=2.69$ (t, $J$ $\left.=7.2 \mathrm{~Hz}, 2 \mathrm{H}, \mathrm{CH}_{2}\right), 2.87\left(\mathrm{t}, J=7.2 \mathrm{~Hz}, 2 \mathrm{H}, \mathrm{CH}_{2}\right), 6.63$ $(\mathrm{d}, J=7.2 \mathrm{~Hz}, 1 \mathrm{H}, \mathrm{ArH}), 6.77(\mathrm{~d}, J=7.2 \mathrm{~Hz}, 1 \mathrm{H}, \mathrm{ArH})$, $6.80(\mathrm{~s}, 1 \mathrm{H}, \beta \mathrm{CH}), 7.33-7.38(\mathrm{~m}, 4 \mathrm{H}, \mathrm{ArH}), 7.50-7.56$ $(\mathrm{m}, 2 \mathrm{H}, \mathrm{ArH}) \mathrm{ppm} .{ }^{13} \mathrm{C} \mathrm{NMR}\left(100.6 \mathrm{MHz}, \mathrm{CD}_{3} \mathrm{OCD}_{3}\right)$ : $\delta=38.62\left(2 \mathrm{CH}_{2}\right), 115.94(\mathrm{CH}), 116.12(\mathrm{CH}), 120.43$ $(\mathrm{CH}), 127.27(\mathrm{C}), 129.30(2 \mathrm{CH}), 129.81(\mathrm{CH}), 130.64$ $(2 \mathrm{CH}), 132.41(\mathrm{CH}), 133.75(\mathrm{C}), 134.83(\mathrm{C}), 144.01(\mathrm{C})$, $145.62(\mathrm{C}), 166.88(\mathrm{C}=\mathrm{O}), 172.47(\mathrm{C}=\mathrm{O}) \mathrm{ppm} . \quad \mathrm{m} / \mathrm{z}$ (HRESI-MS) 328.11742, $\left([\mathrm{M}+\mathrm{H}]^{+}, \quad \mathrm{C}_{18} \mathrm{H}_{18} \mathrm{NO}_{5}\right.$, requires 328.11850 ).

\section{Acknowledgments}

This work received financial support from the Foundation for Science and Technology (FCT, Portugal), through projects UID/QUI/00686/2013, UID/QUI/00686/2016 (CQUM) and UID/QUI/50006/2013-POCI-01-0145-FEDER-007265, cofinanced by European Union (FEDER under the Partnership Agreement PT2020), and from Norte Portugal Regional Operational Programme (NORTE 2020), under the PORTUGAL 2020 Partnership Agreement, through the 
European Regional Development Fund (ERDF) (project NORTE-01-0145-FEDER- 24).

Conflict of Interest: the authors declare that they have no conflict of interest.

This article does not contain any studies with human participants or animals performed by any of the authors.

\section{References}

1. Wei Q-Y, Jiang H, Zhang J-X, Guo P-F, Wang H. Med. Chem. Res. 2012;21:1905-1911.

2. Kwak S-Y, Lee S, Yang JK, Lee Y-S. Food Chem. 2012;130:847-852.

3. Seo H-S, Kwak S-Y, Lee Y-S. Bioorg. Med. Chem. Lett. 2010;20:4266-4272.

4. Kwak S-Y, Seo H-S, Lee Y-S. J. Pept. Sci. 2009;15:634-641.

5. Son S, Lewis BA. J. Agric. Food Chem. 2002;50:468-472.

6. De Baltas P, Bedos-Belval F. Curr. Med. Chem. 2011;18:16721703.

7. Wei Q-Y, Jiang H, Zhang J-X, Zhang C, Guo P-F. Asian J. Chem. 2012;24:2383-2388.

8. Narasimhan B, Belsare D, Pharande D, Mourya V, Dhake A. Eur. J. Med. Chem. 2004;39:827-834.

9. Fu J, Cheng K, Zhang ZM, Fang RQ, Zhu HL. Eur. J. Med. Chem. 2010;45:2638-2643.

10. Chochkova MG, Chorbadzhiyska EY, Ivanova GI, Najdenski H, Ninova M, Milkova T. Nat. Prod. J. 2012;2:50-54.

11. Georgiev L, Chochkova M, Ivanova G, Najdenski H, Ninova M, Milkova T. Riv. Ital. Sost. Grasse 2012;89:91-102.

12. Heijnen CG, Haenen GR, Vekemans JA, Bast A. Environ. Toxicol. Pharmacol. 2001;10:199-206.

13. Negrel J, Javelle F, Paynot M. J. Plant Physiol. 1993;142:518524.

14. Peipp H, Maier W, Schmidt J, Wray V, Strac D. Phytochemistry 1997;44:581-587.

15. Fink W, Liefland M, Mendgen K. Physiol. Mol. Plant Pathol. 1990;37:309-321.

16. Negrel J, Lofty S, Javelle F. J. Plant Physiol. 1995;146:318325.

17. Lee S, Han J-M, Kim H, Kim E, Jeong T-S, Lee WS, Cho K-H. Bioorg. Med. Chem. Lett. 2004;14:4677-4681.

18. Spasova M, Kortenska-Kancheva V, Totseva I, Ivanova G, Georgiev L, Milkova T. J. Peptide Sci. 2006;12.369-375.

19. Georgiev L, Chochkova M, Totseva I, Seizova K, Marinova E, Ivanova G, Ninova M, Najdenski H, Milkova T. Med. Chem. Res. 2013;22:4173-4182.

20. Milde J, Elstner EF, Grassmann J. Mol. Nutr. Food Res. 2007;51:956-961.

21. Milde J, Elstner EF, Grassmann J. Phytomedicine 2004;11:105113.

22. Shi J, Kakuda Y. Herbs: Challenges Chem. Biol. 2006;925:254264.

23. Gonzalez-Perez O, Gonzalez-Castaneda RE. Nutr. Res. 2006;26:1-5.

24. Yogeeta SK, Gnanapragasam A, Kumar SS, Subhashini R, Sathivel A, Devaki T. Mol. Cell. Biochem. 2006;283:139-146.

25. Trombino S, Serini S, Di Nicuolo F, Celleno L, Andò S, Picci N, Calviello G, Palozza P. J. Agric. Food Chem. 2004;52:24112420.

26. Cirico TL, Omaye S. Food Chem. Toxicol. 2006;44:510-516.

27. Yamashita N, Murata M, Inoue S, Burkitt MJ, Milne L, Kawanishi S. Chem. Res. Toxicol. 1998;11:855-862.

28. Flueraru M, Chichirau A, Chepelev LL, Willmore WG, Durst T, Charron M, Barclay LRC, Wright JS. Free Radic. Biol. Med. 2005;39:1368-1377.

29. Silvia V, Baldisserotto A, Scalambra E, Malisardi G, Durini E, Manfredini S. Eur. J. Med. Chem. 2012;50:383-392.

30. Lee BP, Messersmith PB, Israelachvili JN, Waite JH. Annu. Rev. Mater. Res. 2011;41:99-132.

31. Holten-Andersen N, Harrington MJ, Birkedal H, Lee BP, Messersmith PB, Lee KYC, Waite JH. Proc. Natl. Acad. Sci. USA 2011;108:2651-2655.

32. Li L, Yan B, Yang J, Chen L, Zeng H. Adv. Mater. 2015;27:1294-1299.
33. Gilon C, Dechantsreiter MA, Burkhart F, Friedler A, Kessler H. Synthesis of N-alkylated peptides. In: Houben-Weyl: Methods of organic chemistry. Synthesis of peptides and peptidomimetics; Eds.: Goodman M, Felix A, Moroder L, Toniolo C. Thieme Verlag, Stuttgart, New York, E22c: 2003:215-271.

34. Kotha S. Acc. Chem. Res. 2003;36:342-351.

35. Rilatt I, Caggiano L, Jackson RFW. Synlett 2005:2701-2719

36. Dawid S. Amino Acids, 2015;47:1-17.

37. Gupta M, Chauhan VS. Biopolymers, 2011;95:161-173.

38. Rudresh, Ramakumar S, Ramagopal UA, Inai Y, Goel S, Sahal D, Chauhan VS. Structure, 2004;12:389-396.

39. Bierbaum G, Gotz F, Peschel A, Kupke T, VandeKamp M, Sahl HG. Antonie Van Leeuwenhoek 1996;69:119-127.

40. Dunn AD, Corsi CM, Myers HE, Dunn JT. J. Biol. Chem. 1998;273:25223-25229.

41. Paik SH, Chakicherla A, Hansen JN. J. Biol. Chem. 1998;73:23134-23142.

42. Ghoshal AK, Rushmore TH, Buc-Calderon P, Roberfroid M, Farber E. Free Radic. Biol. Med. 1990;8:3-7.

43. Buc-Calderon P, Sipe Jr HJ, Flitter W, Mason RP, Roberfroid M. Chem. Biol. Interact. 1990;73:77-88.

44. Suzen S, Gurkok, G, Coban T. J. Enzyme Inh. Med. Chem. 2006;21:179-185.

45. Stadtman ER, Levine RL. Amino acids 2003;25:207-218.

46. Wagner AF, Demand J, Schilling G, Pils T, Knappe J. Biochem. Biophys. Res. Commun. 1999;254:306-310.

47. Genard S, Galey JB, Hocquaux M. 1999, United States Patent 5871755.

48. Ferreira PMT, Monteiro LS, Coban T, Suzen S. J. Enzyme Inh. Med. Chem. 2009;24:967-971.

49. Vilaça H, Pereira G, Castro TG, Hermenegildo BF, Shi J, Faria TQ, Micaêlo N, Brito RMM, Xu B, Castanheira EMS, Martins JA, Ferreira PMT. J. Mater. Chem. B, 2015;3:6355-636.

50. Vilaça H, Hortelão ACL, Castanheira EMS, Queiroz M-JRP Hilliou L, Hamley I, Martins JA, Ferreira PMT. Biomacromolecules, 2015;16:3562-3673.

51. Ferreira PMT, Maia HLS, Monteiro LS, Sacramento J. J. Chem Soc., Perkin Trans. 1 1999:3697-3703.

52. Ferreira PMT, Monteiro LSM, Pereira G, Silva L, Ribeiro L, Sacramento J. Eur. J. Org. Chem. 2007.5934-5949.

53. Pereira DM, Correia-da-Silva G, Valentão P, Teixeira N, Andrade PB. Combinatorial Chemistry and High Throughput Screening 2014;17:450-457.

54. Grehn L, Gunnarsson K, Ragnarsson U. Acta Chem. Scand. Ser. B, 1987;41:18-23.

55. Lopez-Ayllon BD, Moncho-Amor V, Abarrategi A, Cáceres II, Castro-Carpeño J, Belda-Iniesta C, Perona R, Sastre L. Cancer Medicine 2014:1099-1111. 